\title{
Spatio-temporal Slip, and Stress Level on the Faults within the Western Foothills of Taiwan: Implications for Fault Frictional Properties
}

\author{
Ya-Ju Hsu, ${ }^{1,2}$ Jean-Philippe Avouac, ${ }^{2}$ Shui-Bein Yu, ${ }^{1}$ Chien-Hsin Chang, ${ }^{3}$ Yih-Min Wu, ${ }^{4}$ \\ and JOCHEN WOESSNER ${ }^{2,5}$
}

\begin{abstract}
We use preseismic, coseismic, and postseismic GPS data of the 1999 Chi-Chi earthquake to infer spatio-temporal variation of fault slip and frictional behavior on the Chelungpu fault. The geodetic data shows that coseismic slip during the Chi-Chi earthquake occurred within a patch that was locked in the period preceding the earthquake, and that afterslip occurred dominantly downdip from the ruptured area. To first-order, the observed pattern and the temporal evolution of afterslip is consistent with models of the seismic cycle based on rate-and-state friction. Comparison with the distribution of temperature on the fault derived from thermokinematic modeling shows that aseismic slip becomes dominant where temperature is estimated to exceed $200^{\circ}$ at depth. This inference is consistent with the temperature induced transition from velocity-weakening to velocity-strengthening friction that is observed in laboratory experiments on quartzo-feldspathic rocks. The time evolution of afterslip is consistent with afterslip being governed by velocity-strengthening frictional sliding. The dependency of friction, $\mu$, on the sliding velocity, $V$, is estimated to be $\partial \mu / \partial \ln V=8 \times 10^{-3}$. We report an azimuthal difference of about $10-20^{\circ}$ between preseismic and postseismic GPS velocities, which we interpret to reflect the very low shear stress on the creeping portion of the décollement beneath the Central Range, of the order of 1-3 MPa, implying a very low friction of about 0.01 . This study highlights the importance of temperature and pore pressure in determining fault frictional sliding.
\end{abstract}

Key words: The Chi-Chi earthquake, fault friction, fault rheology, stress, fault slip distribution.

\section{Introduction}

Fault slip occurs as steady aseismic creep or as recurring transient slip, the latter of which might be seismic or aseismic. This process leads to an alternation between long periods of slow elastic strain accumulation, the interseismic period, and short periods of strain release by transient slip events and large earthquakes. An unanswered first-order

\footnotetext{
${ }^{1}$ Institute of Earth Sciences, Academia Sinica, Nankang, Taipei, Taiwan. E-mail: yaru@earth.sinica.edu.tw

${ }^{2}$ Division of Geological and Planetary Sciences, California Institute of Technology, California, U.S.A.

3 Central Weather Bureau, Taipei, Taiwan.

${ }^{4}$ Department of Geosciences, National Taiwan University, Taipei, Taiwan.

5 Swiss Seismological Service, ETH Zürich, Zürich, Switzerland.
} 
question regarding the 'seismic cycle' process is whether asperities, defined loosely here as zones with large coseismic slip (e.g., larger than a given fraction of the peak slip), that broke during large earthquakes, coincide with fault patches that remain locked during the interseismic period. If so, geodetic monitoring of interseismic strain could be used to assess the location and, possibly either the time of a future earthquake or the amount of coseismic slip, hence the magnitude (Shimazaki and NaKATA, 1980).

The fault slip accrues with time depending primarily on the fault friction law and its eventual spatio-temporal variability. Fault friction can be rate-weakening, allowing for stick-slip motion or rate-strengthening promoting aseismic slip (ScHOLZ, 1990). For quartz-feldspathic rocks, rate-strengthening seems to be promoted at high temperature ( $\mathrm{T}>200-250^{\circ} \mathrm{C}$ ), hence at depths deeper than typically $15 \mathrm{~km}$, or for poorly consolidate alluvium or fault gouge at shallow depths (BlANPIED et al., 1995; MARONE, 1998). However, the relation between fault friction and the mode of slip is not trivial. For example, earthquakes can only nucleate in areas obeying a rate-weakening friction law but can propagate dynamically in rate-strengthening areas (LAPUSTA et al., 2000; TsE and RICE, 1986). Furthermore, a fault portion might obey a rate-strengthening friction law but might seem locked if it lies in the stress shadow of a fully locked zone. In that case, it might slip by aseismic afterslip when the stress shadow effect is removed as the shadowing asperities break. For example, it is possible that the shallow portion of subduction zones would dominantly slip aseismically, but would appear locked in the interseismic period as it lies in the shadows of deeper locked patches (BuRGMANN et al., 2005). This mechanism might also explain why shallow creep is rarely observed, except in the case of fault segments which dominantly creep at all depths such as the creeping segment of the San Andreas fault (Burford and Harsh, 1980; Lisowski and Prescott, 1981; Titus et al., 2005) or along the southern portion of the Longitudinal Valley fault in Taiwan (ANGelier et al., 1997; LeE et al., 2001b, 2003; Liu and Yu, 1990; Yu and LiU, 1989; Yu and KuO, 2001).

Another issue, which has been a controversial issue for decades, concerns the stress level under which active faults operate (Scholz, 2000). Deep borehole measurements in a stable tectonic area (BRUdy et al., 1997; ZоBACK and TownEND, 2001) suggest that the differential stress within the brittle crust is generally high, near the threshold of Coulomb failure as obtained from laboratory estimates of the coefficient of friction of rocks which generally range 0.6-0.85 (BYERLEE, 1978). On the other hand, there is evidence that the shear stress acting on major crustal faults is rather small, typically about 10 times less than expected from rock friction experiments. This conclusion is reached particularly for the San Andreas fault zone where frictional heating seems very limited (SHAw, 1995) and where the principal horizontal stress is nearly perpendicular to the fault plane (HAUKSSON, 1990; Jones, 1988; Mount and SupPe, 1987; Zоваск et al., 1987). A low stress level on fault zones has also been deduced from the influence of coseismic stress change due to the Landers earthquake (HARDEBECK and HAUKSSON, 2001) as well as 2002 Denali earthquake (WESSON and BOYD, 2007) on the stress orientations derived from earthquake focal mechanisms. There is more consensus that thrust faults and detachments below 


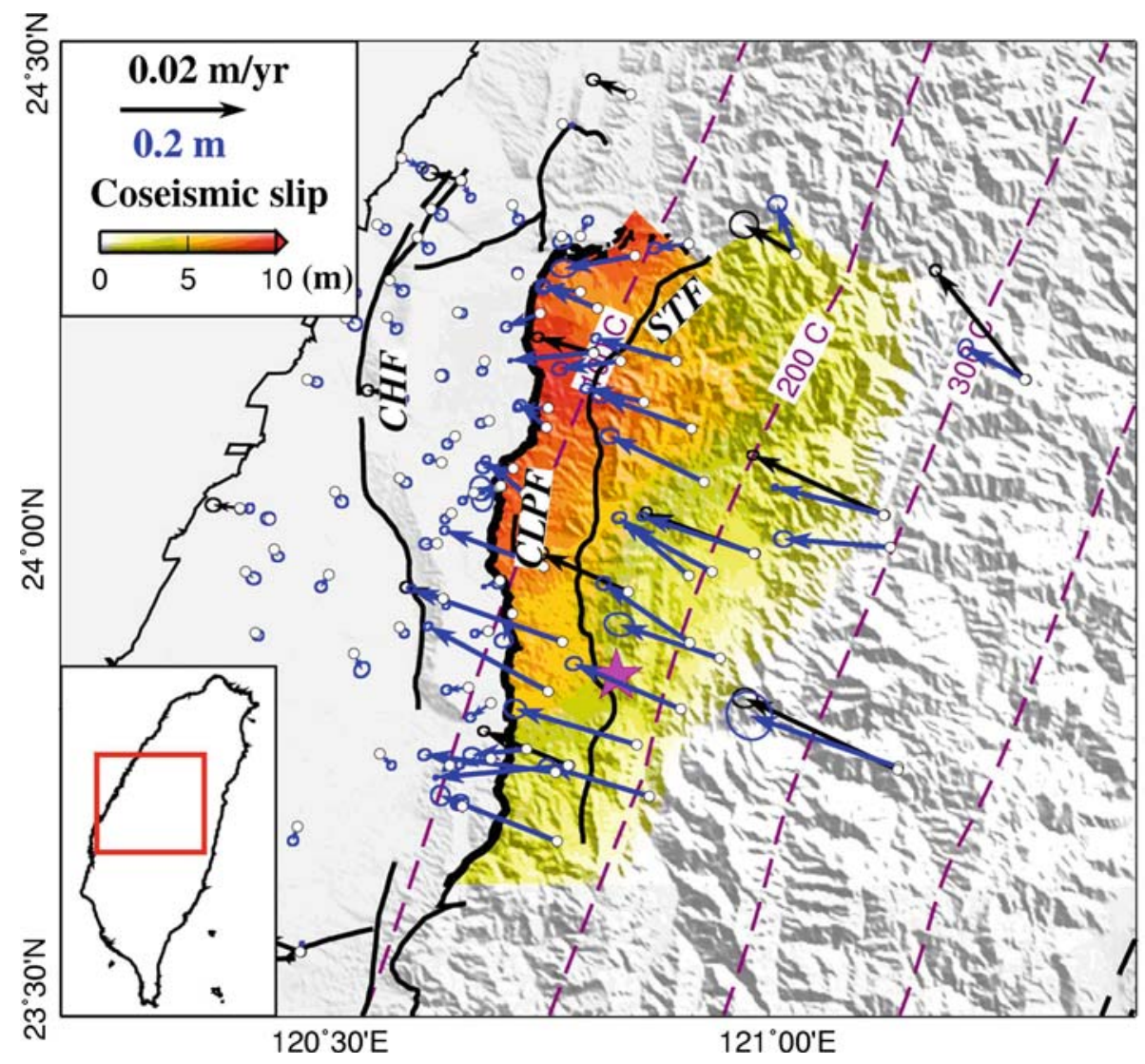

Figure 1

GPS velocities across the western foothills of central Taiwan and coseismic slip distribution of the $1999, \mathbf{M}_{\mathrm{w}}$ 7.6, Chi-Chi earthquake. Black arrows show interseismic GPS velocities (1993-1999), with 95\% confidence ellipses, relative to the permanent GPS stations on Penghu Island before the Chi-Chi earthquake (Yu et al., 2001). Blue arrows indicate postseismic displacement over 15 months following the Chi-Chi earthquake (Yu et al., 2003). Distribution of coseismic slip, derived from inversion of GPS displacements is shown in color. The pink star denotes the epicenter of the Chi-Chi earthquake. Isotherms on the fault (purple dash lines) are derived from the thermo-kinematic model (SimoEs et al., 2007a). Major active faults are indicated as black lines and the 1999 Chi-Chi rupture is shown as a thick black line. CHF: Changhua fault, CLPF: Chelungpu fault, STF:

Shuantung fault.

orogenic wedges, including Taiwan, need to be weak as required from their generally low taper angle (e.g., DAvis et al., 1983; SuPPE, 2007).

We discuss these questions based on the analysis of geodetic strain across the western foothills of Taiwan where $\mathrm{a}_{\mathrm{w}} 7.6$ earthquake occurred in 1999 (Figs. 1 and 2). We take advantage of the wealth of geodetic, seismological and geological data available from this area to investigate the contribution of interseismic slip, afterslip and coseismic slip to the long-term fault slip and the resulting stress transfer. 

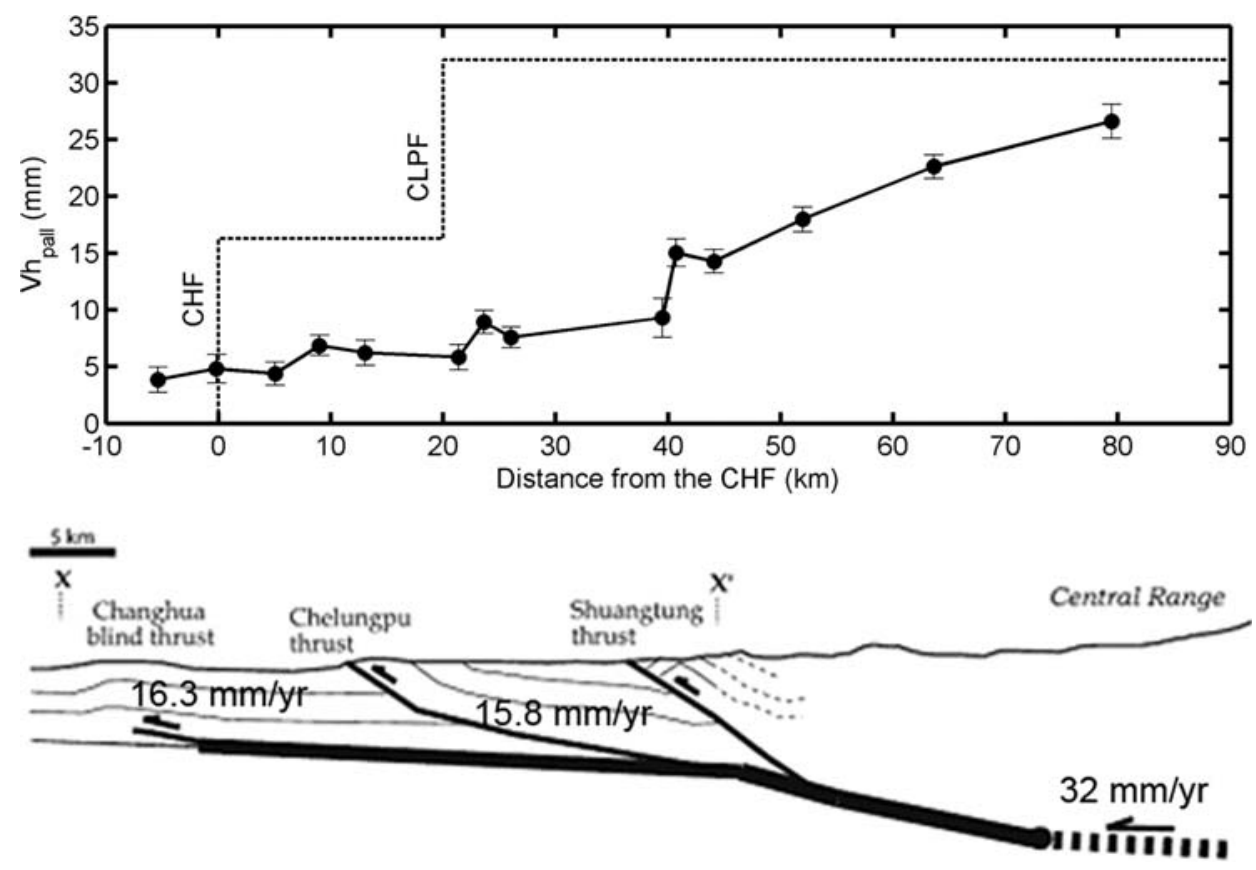

Figure 2

A schematic of interseismic velocity profile parallel to the plate convergence direction and a simplified geological cross section across the western foothills of Taiwan. Studies on the deformed strata terrace inferred slip rates of $16.3 \pm 4.1 \mathrm{~mm} / \mathrm{yr}$ on the Changhua fault (CHF) and $15.8 \pm 5.1 \mathrm{~mm} / \mathrm{yr}$ on the Chelungpu fault (CLPF) (Simoes et al., 2007b). The geological cross section is constrained from numerous seismic profiles in that the faults merge at depth into a single major décollement (YuE et al., 2005). The geodetic data show that the active faults are locked at the surface but some aseismic deformation must occur at depth below the Central Range, probably along the downdip continuation of the décollement (CARENA et al. 2002). The shortening rates across the Changhua and the Chelungpu faults are approximately equal to the geodetic shortening rate across the western foothills, suggesting that little deformation occurs elsewhere, other than on these two major faults.

In the following, we first give an overview of the seismotectonic context of the study area. Next, we analyze the pre-, co-, and postseismic data in a self-consistent manner to assess how fault patches with interseismic, coseismic and postseismic slip pave the fault to contribute to a quasi-uniform slip distribution in the long term and the significance of the difference of azimuth between pre- and postseismic GPS velocities.

\section{Seismotectonic Setting of the Western Foothills of Taiwan}

Three major active faults are recognized along the western foothills of central Taiwan. Seismic profiles and bedding dip angles measured at the surface suggest that they all sole into a single décollement at a depth of about $6 \mathrm{~km}$ (YuE et al., 2005) (Fig. 2). The most frontal fault is the Changhua fault which is a blind thrust fault responsible for the 
formation of Pakuashan anticline at its tip. The shortening rate across Pakuashan is estimated to be $16.3 \pm 4.1 \mathrm{~mm} / \mathrm{yr}$ from the study of dated growth strata deposited over the last $300 \mathrm{ka}$ (SimOes et al., 2007b). The most internal fault is the Shuangtung fault. The Shuangtung fault also deforms recent terraces, but based on its geomorphic expression, it seems to be a second-order feature compared to the two other faults. The Chelungpu fault lies between the Changhua fault and the Shuangtung fault. The shortening rate across the Chelungpu fault is estimated to be $15.8 \pm 5.1 \mathrm{~mm} / \mathrm{yr}$ from the deformation of dated Holocene terraces (SimOES et al., 2007b).

GPS data acquired over the years preceding the Chi-Chi earthquake (Yu et al., 2001) indicate a shortening rate across the western foothills approximately equal to the sum of the long-term shortening rates across Pakuashan anticline and Chelungpu fault (Fig. 2). It follows that the $\sim 30 \mathrm{~mm} / \mathrm{yr}$ shortening rate across the western foothills has to be taken up by either aseismic or seismic slip on the Chelungpu and Changhua faults and their downdip continuation as a décollement (or as a shear zone with finite thickness).

The $\mathrm{M}_{\mathrm{w}}$ 7.6, 1999 Chi-Chi earthquake ruptured the Chelungpu thrust fault along the western foothills of Taiwan extending approximately $100-\mathrm{km}$-long with up to $10-15 \mathrm{~m}$ of coseismic slip (Ji et al., 2001; Johnson et al., 2001; SHIn and TENG, 2001). GPS data acquired over the years preceding the Chi-Chi earthquake (YU et al., 2001) indicate that the area with significant coseismic slip is primarily locked before the main shock (Dominguez et al., 2003; Hsu et al., 2003; LoevenBRuck et al., 2001). GPS data acquired after the main shock shows postseismic deformation reflecting dominantly afterslip downdip from the coseismic rupture area (Hsu et al., 2002, 2007; Yu et al., 2003).

GPS measurements also reveal a systematic counter-clockwise rotation of postseismic surface displacements relative to interseismic velocities at the sites within the Central Range (Fig. 1). The azimuthal differences between preseismic and postseismic GPS velocities are only marginally significant at each single site where both pre- and postChi-Chi measurements are available. The fact that the postseismic azimuth is systematically rotated counter-clockwise at all GPS sites located within the range is an indication that this rotation is probably not fortuitous, however. The possibility that the difference of azimuth can be a reference frame issue can be excluded since the interseismic and postseismic GPS data were processed using identical procedures and the same reference frames (International Terrestrial Reference Frame 1997, ITRF97) (Yu et al., 2001, 2003). We analyze below the significance of this observation.

\section{Modeling of Geodetic Strain}

\subsection{Method and Data}

The geodetic data used in this study include coseismic displacements ( $\mathrm{YU}$ et al., 2001), the postseismic GPS displacements recorded over 15 months after the mainshock 


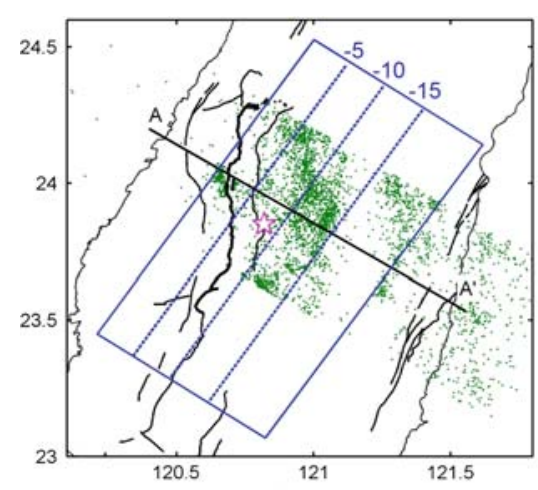

(a)

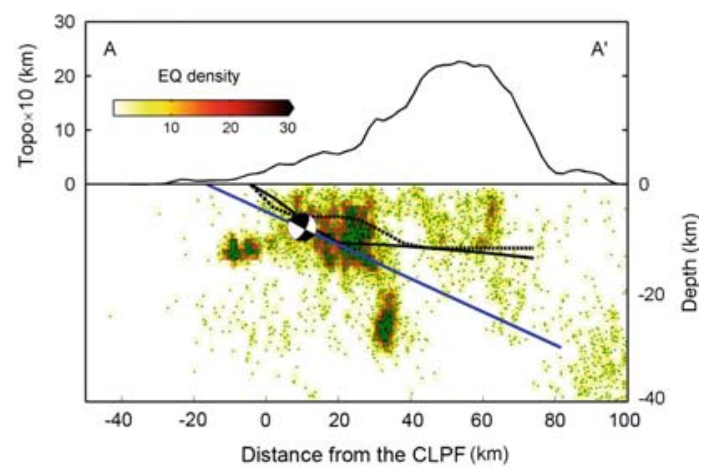

(b)

Figure 3

Geometries of the Chelungpu fault, and of the simplified planar fault used to model interseismic strain from a forward slip modeling approach. (a) The green circles denote aftershocks within a $60-\mathrm{km}$ wide swath in the first 15 months after the Chi-Chi main shock. A-A' and blue rectangle indicate a NW-SE trending transect of the modeled Chelungpu fault and the simplified planar fault. Blue dash lines denote iso-depth contours of the simplified planar fault. The depth in kilometer is shown as a blue number. (b) The depth profiles along A-A' indicated in (a). The black solid and dash lines indicate the fault geometries determined by inversions and YUE et al. (2005), respectively. The blue line denotes the fault geometry of the simplified planar fault used to model interseismic strain. Color scale indicates the earthquake density (number of event/ $\mathrm{km}^{2}$ ). The beach ball shows the focal mechanism of the Chi-Chi main shock.

(Yu et al., 2003), and GPS site velocities collected before the Chi-Chi earthquake that consists of 12 campaign-mode sites and two permanent sites (Yu et al., 2001).

For the purpose of this study, we model the interseismic GPS velocities (1993-1999) and the postseismic GPS displacements (over the 15 months following the Chi-Chi earthquake) in a self-consistent manner, i.e, assuming the same geometry for the décollement and using the same modeling technique.

We first utilized the 3-D fault geometry constrained by surface geology, seismic profiles, well data and geological balanced cross sections proposed by YUE et al. (2005) (black dashed line in Fig. 3b). The fault geometry is well constrained beneath the western foothills from reliable seismic data and surface structural constraints. It is assumed that the fault extends eastward beneath the Central Range as a décollement at a relatively shallow depth as suggested from relocated seismicity (CARENA et al., 2002). Because the geometry of the fault beneath the Central Range is not that well constrained, we also searched for the geometry that best fits the geodetic data (black solid line in Fig. 3b). It should be pointed out that the model assumes that deformation at depth can be represented by fault slip on a localized décollement. In reality, it is probable that deformation is more distributed than we assume and that some amount of pure shear must be taking place to allow shortening and thickening of the crust beneath the range. The décollement is therefore a convenient representation of deformation at depth although not necessarily a very realistic representation. 
The fault is subdivided into $\sim 150$ small rectangular patches with sizes ranging from $5 \mathrm{~km} \times 5 \mathrm{~km}$ to $8 \mathrm{~km} \times 8 \mathrm{~km}$. This representation of the fault was found to be a reasonable compromise so that the fault model follows reasonably well the sinuous fault trace as observed in the field, and its spatial extent is large enough to allow modeling coseismic, postseismic, and interseismic slip. The Green functions, i.e., the surface displacements at the sites of observations related to unit slip vectors with either pure dipslip or pure strike-slip components, are computed from the theory of elastic dislocation in an elastic half space (OKADA, 1985). The rigidity modulus is fixed to a standard value of $30 \mathrm{GPa}$. Because the preseismic and postseismic displacements show relatively stable azimuths (Hsu et al., 2007; Yu et al., 2001), we ignore temporal variations of rake during interseismic or postseismic deformation. Furthermore, we ascertained that the interseismic data can be fitted reasonably well without introducing spatial variations in rake.

The data are inverted using a weighted least-squares approach by minimizing the following functional:

$$
F(\boldsymbol{s}, \alpha, \beta, \boldsymbol{m})=\left\|\sum^{-1 / 2}(G(\boldsymbol{m}) \boldsymbol{s}-\boldsymbol{d})\right\|^{2}+\alpha^{-2}\left\|\nabla^{2} \boldsymbol{s}\right\|^{2}+\beta^{-2}\|\boldsymbol{s}\|^{2},
$$

where $\Sigma^{-1 / 2}$ is the inverse square-root of the data covariance matrix; $G(\boldsymbol{m})$ are Green's functions which depend on the fault geometry parameters $\boldsymbol{m} ; \boldsymbol{s}$ is slip; $\boldsymbol{d}$ is the observed displacements and $\nabla^{2}$ is the finite-difference approximation of the Laplacian smoothing operator. To regularize the inversions, we use two damping parameters which characterizes the weights put on the model smoothness, $\alpha$, and on minimizing the geodetic moments, $\beta$, and they are determined by cross validation (MATTHEws and Segall, 1993). The fit to the data is quantified from the mean of the normalized square residuals defined as:

$$
\chi_{r}^{2}=\frac{1}{N}\left\|\sum^{-1 / 2}(G(\boldsymbol{m}) \boldsymbol{s}-\boldsymbol{d})\right\|^{2}=\frac{1}{N} \sum_{i=1}^{N}\left(\frac{d_{i}^{\text {obs }}-d_{i}^{\text {pred }}}{\sigma_{i}}\right)^{2},
$$

where $N$ is the number of data points; $\sigma_{i}$ is the $67 \%$ uncertainty on the $i$-th data point; $d_{i}^{\text {obs }}, d_{i}^{\text {pred }}$ are the observed and predicted values on the $i$-th data point. A value of 1 of $\chi_{r}^{2}$ means that the model fits the data within uncertainties on average. Note that although this quantity, $\chi_{r}^{2}$, resembles the reduced chi-square, it does not have the same statistical significance since the number of model parameters is not considered.

\subsection{Coseismic Slip Model}

The coseismic slip model obtained using the 3-D fault geometry proposed by YUE et al. (2005) yields $\chi_{r}^{2}$ of 599 (black dashed line, Fig. 3b). The weighted root-meansquare misfit (wrms) of the horizontal and vertical displacements are $0.15 \mathrm{~m}$ and $0.21 \mathrm{~m}$, respectively, about 10-20 times the estimated uncertainties. If the fault geometry beneath 


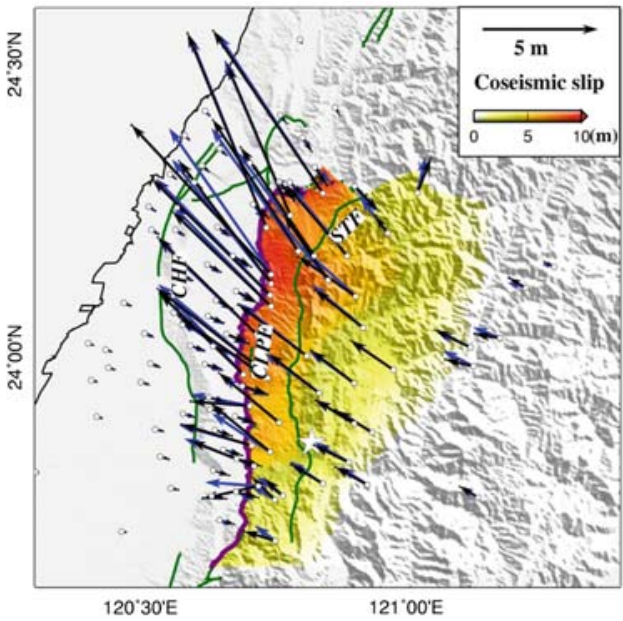

(a)

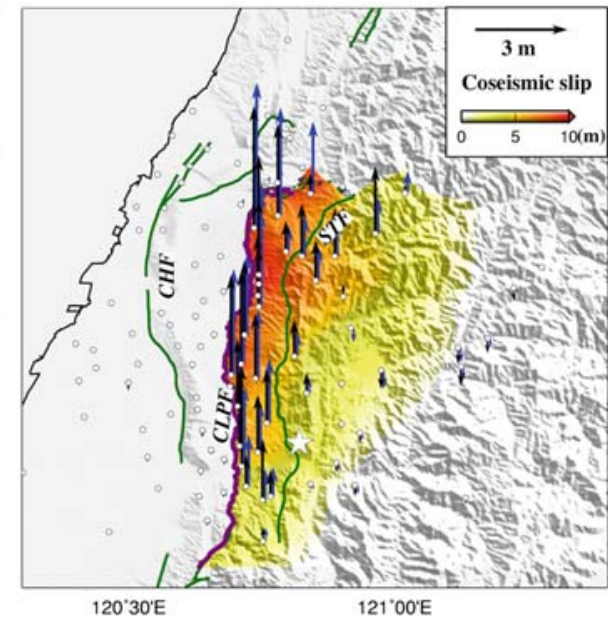

(b)

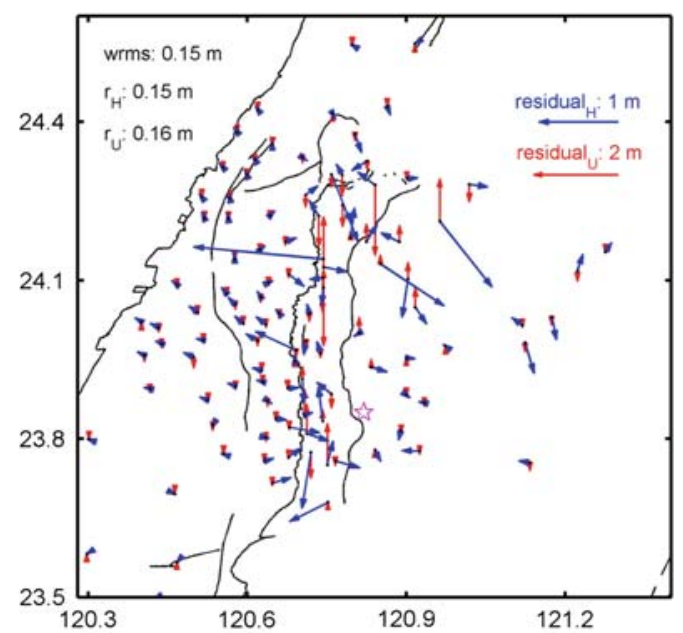

(c)

Figure 4

Coseismic slip distribution of the $1999 \mathrm{M}_{\mathrm{w}}$ 7.6 Chi-Chi earthquake. (a) Black and blue arrows indicate observed coseismic horizontal displacements (YU et al., 2001) and predictions from our best-fitting coseismic slip model. Color indicates coseismic slip. White star indicates the epicenter of the Chi-Chi earthquake. (b) Vertical displacements. Major faults are indicated as green lines and the 1999 Chi-Chi rupture is shown as a purple line. (c) Residuals of horizontal (blue) and vertical (red) displacements.

the Central Range is optimized (black solid line, Fig. 3b), the misfit, $\chi_{r}^{2}$, is reduced to 499 (Fig. 4). Figure $4 \mathrm{c}$ shows the residuals between the observed displacements and those computed from the optimal coseismic model. Although the residuals are larger than the data uncertainties on average, these residuals manifest no systematic pattern that could 


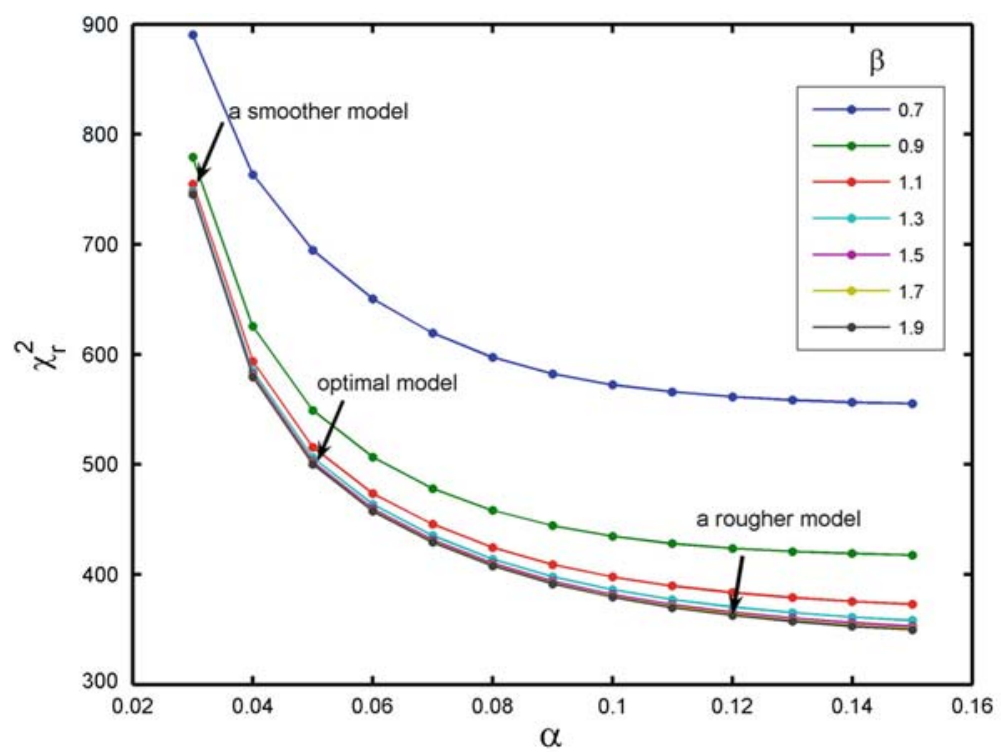

(a)

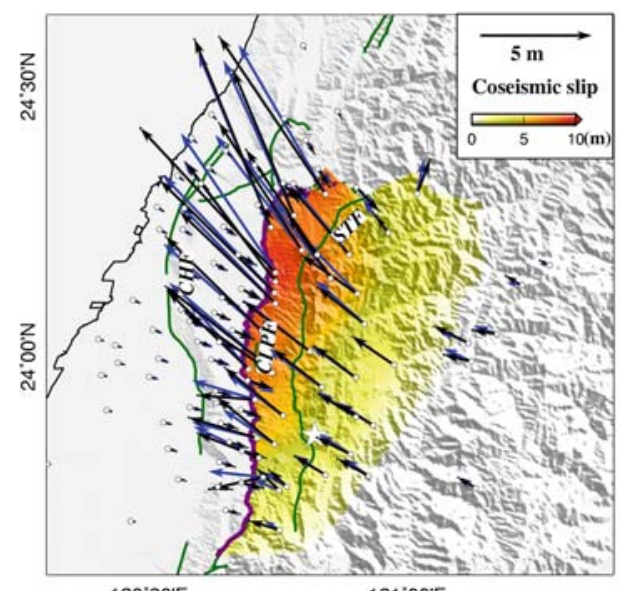

$120^{\circ} 30^{\prime} \mathrm{E}$

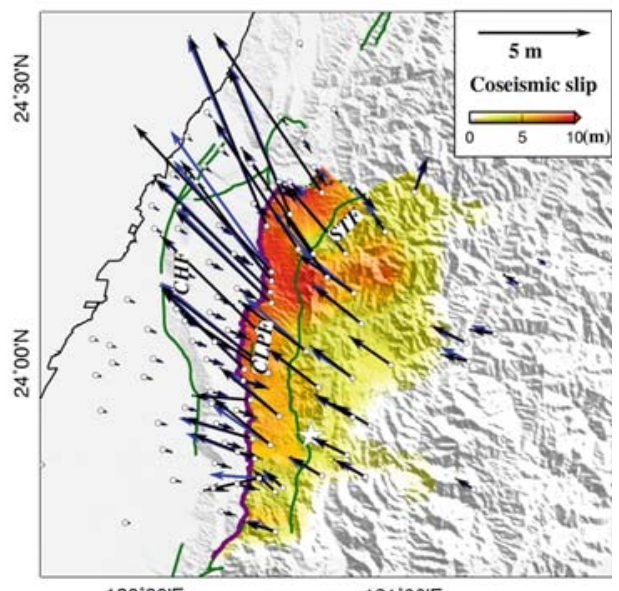

(c) $121^{\circ} 00^{\prime} \mathrm{E}$

c)

(b)

Figure 5

(a) Plot showing how the value of the $\chi_{r}^{2}$ (see equation (2)) evolves as a function of the weight put on the model smoothness (proportional to $1 / \alpha$ ) and on minimizing the geodetic moment (proportional to $1 / \beta$ ). (b) Black and blue arrows indicate observed coseismic horizontal displacements (YU et al., 2001) and predictions from the smoother coseismic slip model indicated in (a). (c) Same as (b) but for the rougher slip model indicated in (a).

inspire improvement of the fit further. Figure 5a shows how the fit to the data evolves as a function of the weight put on the model smoothness (proportional to $1 / \alpha$ ) and on minimizing the geodetic moment (proportional to $1 / \beta$ ). Figures $5 b$ and $5 c$ show the slip 
Table 1

The reduced-chi-squares $\left(\chi_{r}^{2}\right)$, geodetic moment and the rate of moment deficit in coseismic, postseismic, and interseismic slip models

\begin{tabular}{|c|c|c|c|c|c|}
\hline & \multirow{2}{*}{$\begin{array}{c}\text { Coseismic } \\
\text { model }\end{array}$} & \multirow{2}{*}{$\begin{array}{l}\text { Postseismic } \\
\text { model }\end{array}$} & \multicolumn{3}{|c|}{ Interseismic model } \\
\hline & & & Model 1 & Model 2 & Model 3 \\
\hline $\begin{array}{l}\chi_{r}^{2} \\
\text { Geodetic moment/ } \\
\text { moment rate }\end{array}$ & $\begin{array}{c}499 \\
3.6 \times 10^{20} \\
(\mathrm{~N} \mathrm{~m})\end{array}$ & $\begin{array}{c}8.5 \\
3.9 \times 10^{19} \\
(\mathrm{~N} \mathrm{~m})\end{array}$ & $\begin{array}{c}24.5 \\
1.2 \times 10^{18} \\
(\mathrm{~N} \mathrm{~m} / \mathrm{yr})\end{array}$ & $\begin{array}{c}10.9 \\
2.3 \times 10^{18} \\
(\mathrm{~N} \mathrm{~m} / \mathrm{yr})\end{array}$ & $\begin{array}{c}2.7 \\
3.7 \times 10^{18} \\
(\mathrm{~N} \mathrm{~m} / \mathrm{yr})\end{array}$ \\
\hline
\end{tabular}

distributions obtained for alternative models smoother and rougher, respectively, than the preferred model of Figure 4. It ensures that even if the slip distribution is allowed to be rougher than that of the preferred model, the fit to the data does not improve substantially. There is therefore no obvious way to improve the fit to the data within the framework of our modeling which assumes that the surface deformation is due to slip on a single fault embedded in a homogeneous elastic half space. The three models shown in Figures 4 and 5 are only marginally different. We conclude that the preferred model is a robust firstorder representation of the main characteristics of the coseismic slip distribution.

The optimal fault geometry places the décollement at a depth of $\sim 12 \mathrm{~km} \mathrm{depth}$, considerably deeper than the 5-6 km depth proposed by YuE et al. (2005). This value is more consistent with the hypocentral depth of the Chi-Chi earthquake main shock and the depth distribution of aftershocks (Chang et al., 2007). Our fault geometry in fact approaches YUE et al.'s alternative fault model which was proposed to better reconcile the structural constraints with the main shock hypocenter (Fig. 21, YuE et al., 2005). The fit to the geodetic data remains, deficient, corresponding to a wrms of 0.15 (Fig. 4c), however this model does fit the data better than the models in previous studies. For example, JoHnson et al. (2001) reported a wrms of $0.19 \mathrm{~m}$ obtained from a homogeneous elastic half-space model and JoHnson and SEGALL (2004) obtained wrms values between $0.155 \mathrm{~m}$ and $0.17 \mathrm{~m}$ from layered elastic models, with eventual lateral material contrast across the fault. Reconciling the geodetic data and the structural constraints on the Chelungpu fault geometry would probably require allowing for variations of elastics properties in 3-D and eventual anelastic deformation off the main fault zone. Nonelastic deformation of the footwall has indeed been documented in the field and is an expected feature given the nonplanar geometry of the fault (CHEN et al., 2007b). These sophistications are beyond the scope of this study. Also it is possible that the uncertainties assigned to the coseismic displacements may be underestimated.

Most of coseismic slip is shallow with a maximum near the surface and a gradual downdip decrease to negligible slip at about $10 \mathrm{~km}$ depth (Fig. 4). The maximum slip in our best-fitting model is $10 \mathrm{~m}$, located at the northwestern edge of the fault. The slip potency is $11873 \mathrm{~km}^{2}-\mathrm{m}$, corresponding to a moment of $3.6 \times 10^{20} \mathrm{~N}-\mathrm{m}$ (Table 1), which is somewhat larger than the value of $2.7 \times 10^{20} \mathrm{~N}-\mathrm{m}$ estimated from the joint 
inversion of geodetic and seismological data (JI et al., 2003), but close to the scalar moment of $3.4 \times 10^{20} \mathrm{~N}$-m of the Harvard CMT solution.

Our coseismic slip distribution is quite similar to those obtained in the previous studies that were based on the same GPS data set (JoHnson et al., 2001; Johnson and Segall, 2004) or jointly with remote sensing data (Dominguez et al., 2003; Loevenbruck et al., 2004) or seismological data (J et al., 2003), which all yielded misfits similar to those obtained with our modeling. In these other models, the fault geometry is similar with the strike approximately $\mathrm{N}-\mathrm{S}$ and dip $30^{\circ}$ to the east. All these models use a homogeneous earth model, except in the cases of Ji et al. (2003) which assume a layered earth model and JoHNSON and SEGALL (2004) which explores different layered structures with lateral contrast. Despite different assumptions and data sets used in these models, they all show slip distributions similar to the one we have obtained with a maximum coseismic slip generally between 10 and $15 \mathrm{~m}$ on the shallow northern portion of the Chelungpu fault.

\subsection{Afterslip Model}

We compute the afterslip model corresponding to cumulative slip over 15 months using the same procedures as that used to derive the coseismic slip model. Figure 6 shows the corresponding afterslip distribution. The fit to the surface postseismic displacements corresponds to a $\chi_{r}^{2}$ of 8.5 (Table 1). The less satisfactory fit is likely because our model accounts only for afterslip while other processes such as poroelastic effect and postseismic viscous relaxation probably also contribute. However, it is clear that afterslip is the dominant source of the observed postseismic surface strain (Hsu et al., 2007). In our model, afterslip over the 15 months following the Chi-Chi earthquake released a cumulative moment of $3.9 \times 10^{19} \mathrm{~N}-\mathrm{m}$, constituting about $11 \%$ of the coseismic moment.

\subsection{Interseismic Model}

The interseismic and postseismic geodetic data show a gradual increase of horizontal velocities relative to the foreland across the Central Range, consistent with elastic deformation of the crust driven by aseismic creep along a basal décollement, while shallow faults remain locked. To first order, the geodetic data can thus be modeled reasonably well assuming that the shallow portion of the décollement is fully locked (creep rate is zero) until it reaches some depth that is adjusted to best fit the geodetic observations (Dominguez et al., 2003; Hsu et al., 2003; LOEVENBRUCK et al., 2001).

One difficulty arises because both the Changhua and the Chelungpu faults might be considered. In theory, if creep occurs only downdip of where they merge into their common décollement, the models obtained using one, the other or both faults should be equivalent. This is because the geometry of any fully locked fault should not matter since it does not creep and hence does not contribute to interseismic strain. This is 


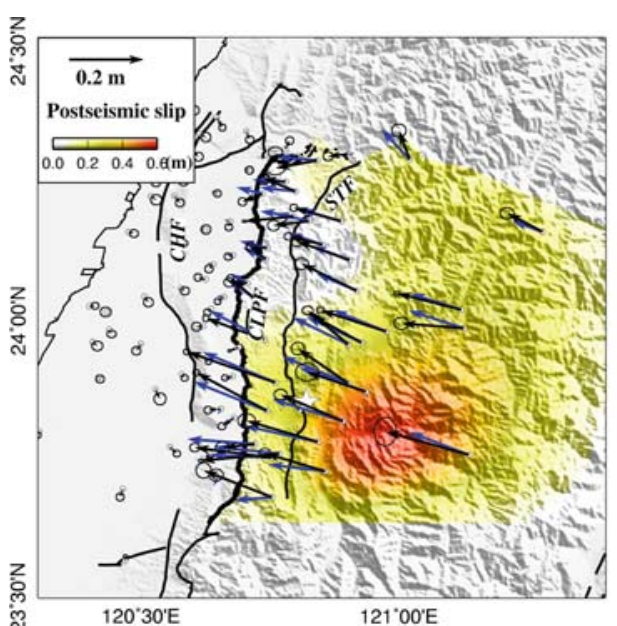

(a)

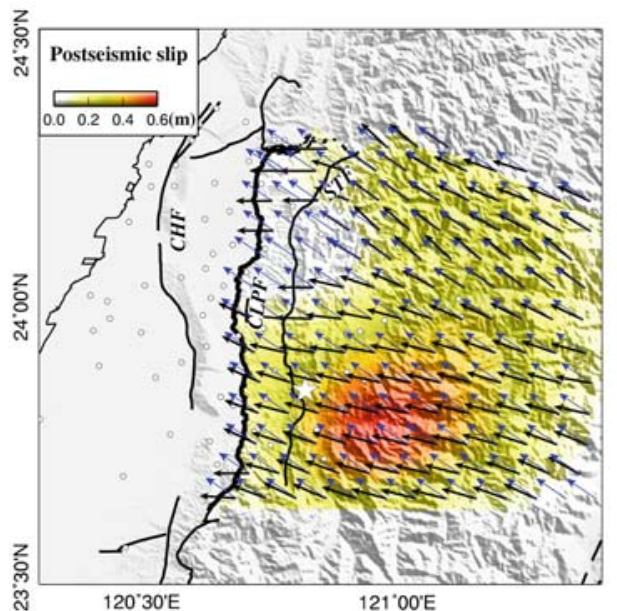

(c)

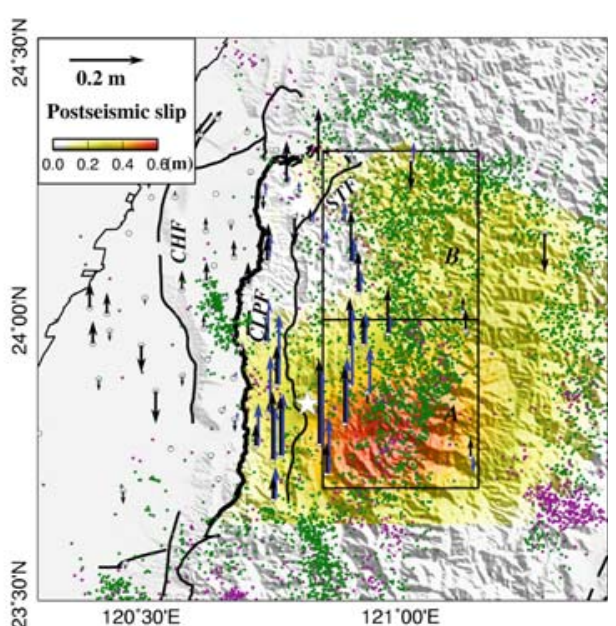

(b)

\section{Figure 6}

Postseismic slip distribution of the Chi-Chi earthquake (a) Black and blue arrows indicate observed (Yu et al., 2003) and predicted postseismic horizontal displacements. Color indicates cumulative postseismic slip over a 15-month period following the main shock. White star shows the epicenter of the Chi-Chi earthquake. (b) Vertical displacements. Black boxes indicate the two regions ( $A$ : south, $B$ : north) within which the stress tensor is determined from earthquake focal mechanisms. Purple circles denote the seismicity between 1992 and 1999.7, before the Chi-Chi main shock. Green circles denote the seismicity between 1999.7 and 2001, after the Chi-Chi main shock. (Data from the Central Weather Bureau in Taiwan) (c) Azimuths of postseismic (black vectors) and interseismic (blue vectors) fault slip vectors.

approximately the case here and we therefore ignore the Changhua fault in the modeling of the interseismic strain. This is equivalent to assuming that the Changhua fault is fully locked entirely to where it merges with the Chelungpu fault. Note however that when it 
comes to estimating the rate of accumulation of moment deficit in the interseismic period, it is important to take into account real fault geometries and how slip rate on the décollement is partitioned between slip on the Changhua fault and on the Chelungpu fault.

Either a backslip (SAVAGE, 1983) or a forward slip modeling approach can be adopted to provide for the interseismic slip rate distribution. In the present context, the main advantage of the backslip model is that the area that needs to be modeled is small. However, the backslip model assumes that no elastic strain accumulates over the long term; an assumption that holds only if the creeping fault is strictly planar. Comparisons with finite-element modeling of the seismic cycle on a thrust fault in which distributed inelastic deformation and erosion is allowed, have shown that both the forward slip and the backslip approaches are reasonable first-order approximations, given that the geometry of the creeping fault is close enough to planar (VERGNE et al., 2001). The most important difference between the two approaches lies in their opposite edge effects. With the backslip model, areas of the fault that are not explicitly modeled (at depths or laterally) are implicitly assumed to creep at the long-term slip rate; while they are implicitly assumed to be locked in the forward slip model. Here, we use both approaches and compare their results. We present in fact three interseismic models. The first two are obtained from a backslip modeling approach employing a fault geometry consistent with that used for the modeling of coseismic and postseismic deformation. In these two models, the long-term slip rate is assumed to be constant $(30 \mathrm{~mm} / \mathrm{yr})$ and the rake is uniform, set to an optimum value of $304^{\circ}$ obtained from a grid search. Because the Chelungpu fault is non-planar, the backslip approach is not well justified. The long-term elastic strain accumulation leads to very large stresses, violating the assumption that long-term deformation does not lead to strain. We therefore also produce a model from a forward slip modeling approach. In that case, we additionally optimize the fault geometry to fit the geodetic data best.

In Model 1, we test the hypothesis that the slip distribution due to the Chi-Chi earthquake would mirror the interseismic slip rate pattern. To do so, we consider a backslip model in which the fault moves backward at a rate proportional to the sum of the coseismic slip and afterslip models. In that case, the only parameter is the 'long-term' slip rate. A long-term slip rate of $30 \mathrm{~mm} / \mathrm{yr}$ yields the best fit to the data (Fig. 7a) that corresponds to a $\chi_{r}^{2}$ of 24.5 (Table 1 ). The fit is not very satisfactory, particularly because the model predicts too much creep along the northern and southern segments of the Chelungpu fault (Fig. 7a). We conclude that the coseismic plus postseismic slip model is not exactly proportional to the interseismic slip deficit.

Model 2 (Fig. 7b) was obtained by inverting for the best-fitting backslip distribution. Here we used a fault geometry slightly different from the one for the coseismic and postseismic models. To avoid the change of the fault strike on the northern Chelungpu fault, we connect the Chelungpu fault to the Sanyi fault northward. The optimal slip model corresponds to a $\chi_{r}^{2}$ of 10.9 (Table 1). The slip distribution obtained from this approach shows strong locking of most of the area that ruptured during the Chi-Chi 

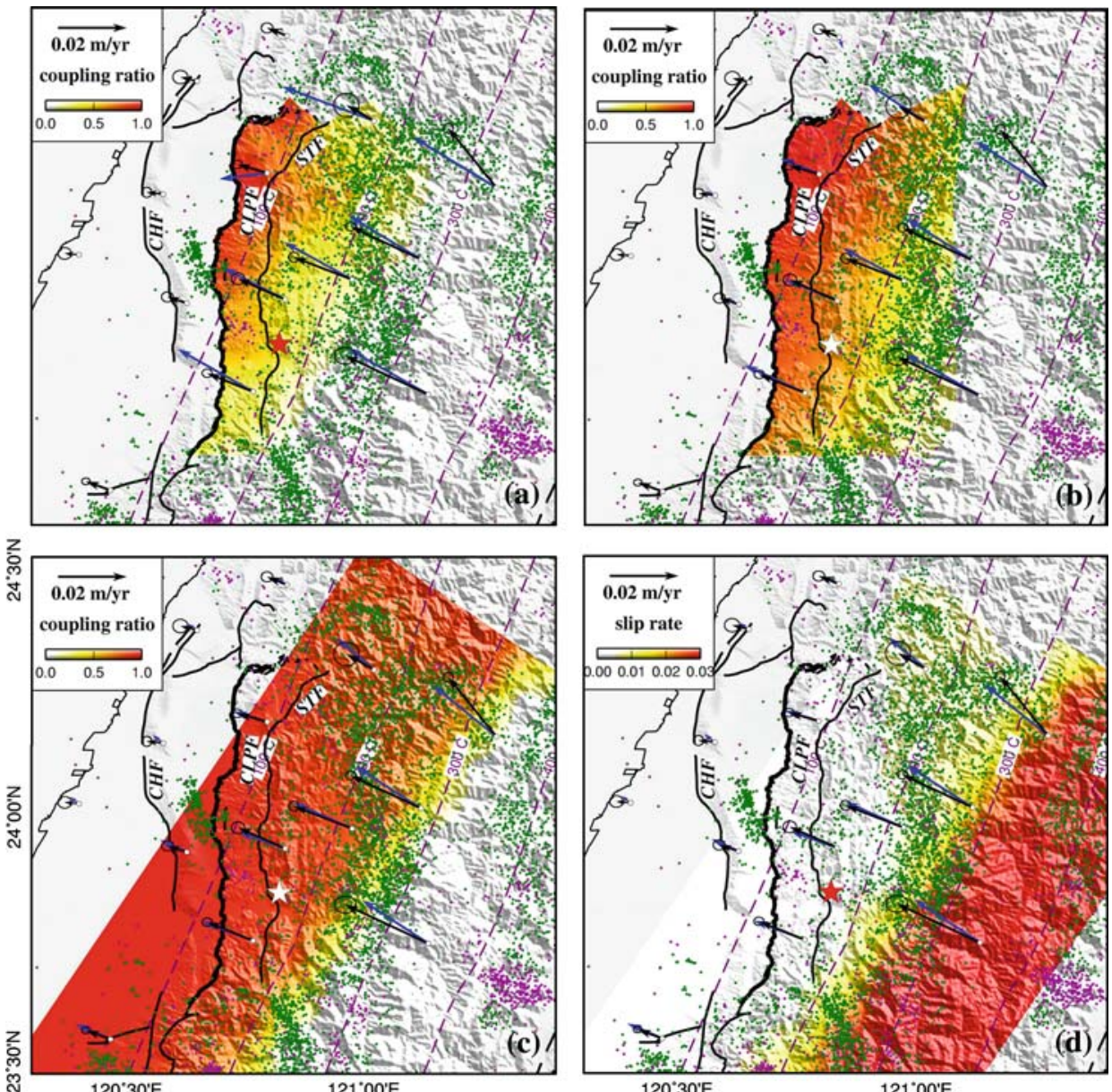

Figure 7

Interseismic coupling, observed and predicted interseismic horizontal surface velocities. The coupling ratio is defined as 1 minus the ratio of the interseismic creep rate to the long-term creep rate ( $30 \mathrm{~mm} / \mathrm{yr})$. Purple and green dots show earthquakes with $\mathrm{M}_{\mathrm{L}}>3$ recorded between 1993 and 1999.7, and between 1999.7 and 2001 (data from the Central Weather Bureau), respectively. The models in (a) and (b) were obtained from a backslip modeling approach (SAVAGE, 1983) based on the coseismic fault geometry. The model in (a) assumes a backslip distribution exactly matches the sum of coseismic slip and afterslip distributions on the Chelungpu fault. The model in (b) was obtained from least-squares adjustment of the backslip distribution. The model in (c) was obtained from the inversion of fault creep rate on the décollement, using a forward slip modeling approach. The corresponding creep rate distribution is shown in (d). The reduced chi-square values corresponding to these models are listed in Table 1. Note that, as noticed in an earlier study (Dominguez et al., 2003), that seismicity follows quite closely the downdip edge of the locked fault zone. Isotherms on the fault (purple dash lines) are derived from the thermo-kinematic model (SIMOES et al., 2007a).

earthquake. The main differences compared with the previous model are that the slip distribution is less compact and that locking is stronger on the southern part of the Chelungpu fault where only limited moment was released in 1999. The misfits at the 
northernmost sites are probably due to the fact that the fault area beyond the northern limit of the model is implicitly assumed to be creeping, while it is probably partly locked in reality.

Model 3 (Fig. 7c) was obtained from the inversion of the surface velocities from a forward slip modeling approach. The geometry of the décollement and its continuation beneath the Central Range is approximated using a single planar fault (blue rectangle in Fig. 3a). We search for the optimal fault geometry where interseismic slip occurred as a uniform rate of $30 \mathrm{~mm} / \mathrm{yr}$ in the direction of $304^{\circ}$. The best-fitting model corresponds to a décollement striking $34^{\circ}$, and dipping $17^{\circ}$ to the east (Fig. 3). The fault extends somewhat deeper with a dip more steeply than the décollement inferred from the modeling of the coseismic deformation, but both meet with the ramp of the Chelungpu fault at a depth of $14 \mathrm{~km}$ (Fig. 3b). We impose a uniform slip rate of $30 \mathrm{~mm} / \mathrm{yr}$ in the direction of $304^{\circ}$ on the fault deeper than the locking depth $(14 \mathrm{~km})$ and predicted surface velocities on GPS sites. We then invert for a slip model on the westward continuation of the décollement using the residual velocity field. The optimal interseismic slip distribution is the sum of the uniform slip model and residual slip model. The fit to the data corresponds to a $\chi_{r}^{2}$ of 2.7. The spatial distribution is similar to that obtained in Model 2. The result in Model 3, like Model 2, also requires strong locking at the south, although the width of the locked zone is significantly narrower than that to the north. The coupling pattern resembles the distribution of coseismic slip, although it extends somewhat deeper where most afterslip occurred.

Seismicity in the interseismic and postseismic periods appears to be clustered along the downdip edge of the locked fault zone (Fig. 7). That is, the seismicity clearly follows the boundary between the locked fault zone and the creeping décollement. This was noticed first by Dominguez et al. (2003) who suggested that, as observed in the Himalaya (Bollinger et al., 2004; Cattin and Avouac, 2000), seismicity would be triggered by stress build up near the up-dip edge of the creeping zone.

\section{Estimation of the Stress Level Associated to the Décollement beneath the Central Range}

The interseismic model predicts slip on the décollement striking $304^{\circ}$, approximately parallel to the convergence between the Philippine Sea Plate and South China, while the postseismic model yields slip striking about $275^{\circ}$, if assumed uniform (Fig. 8). Slip on the basal décollement (or equivalently a shear zone with a finite width) should be colinear with the shear stress acting on it. Following a reasoning similar to that of HARDEBECK and Hauksson (2001), who analyzed the stress change due to the Landers earthquake using earthquake focal mechanisms, the difference of azimuth between interseismic velocities and postseismic displacements, if significant, suggests a coseismic stress change of the order of magnitude of the preseismic stress on the décollement. 


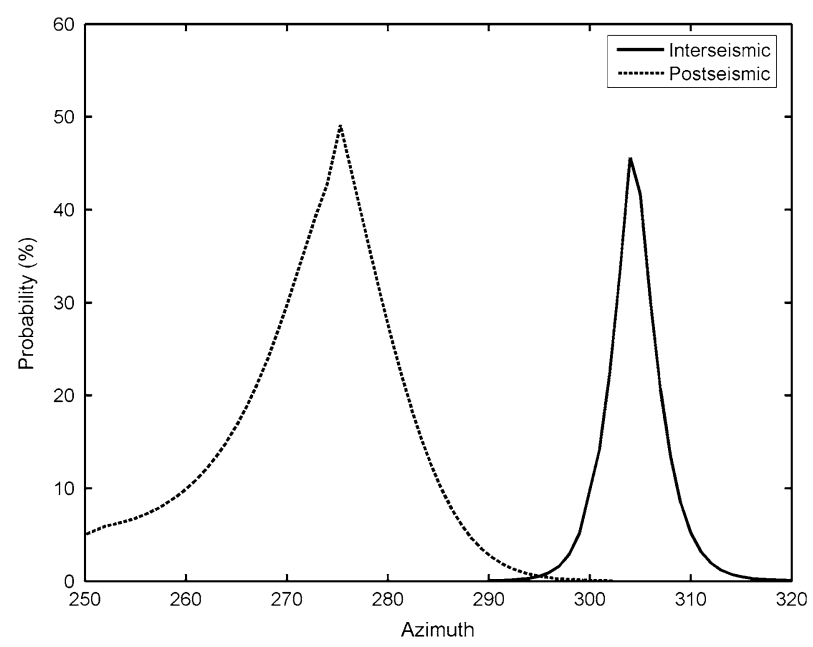

Figure 8

Azimuth of slip on the décollement inferred from the inversion of the interseismic and of the postseismic data. These inversions are conducted assuming a uniform rake. The t-test is used to estimate the probability distribution.

\subsection{Significance of the Difference between Preseismic and Postseismic Azimuths}

In order to test the significance of the difference of rakes between preseismic and postseismic models, we have run inversions of the interseismic GPS data and of the postseismic data assuming a uniform rake that was varied between $250^{\circ}$ and $320^{\circ}$ (Fig. 8). Using the t-test, we estimate the probability of rejection of any particular value of the slip azimuth in view of the fit obtained to either the interseismic or postseismic data. The uniform rake that best fit the interseismic data is $304^{\circ}$ and the one that best fit the postseismic data is $275^{\circ}$. The t-test shows that the probability that the post- and the interseismic data reflect a slip distribution with the same rake, assumed uniform, is less than 5\%. This shows that the rakes required to fit the postseismic and the interseismic data do differ significantly. If we believe that the assumption of uniform rake is valid and that formal uncertainties on the GPS data are reasonably well estimated, the difference of slip rakes in the interseismic and postseismic periods is found to be significant from 0 at the $95 \%$ confidence level. However, it should be realized that the rake might not be uniform and that interseismic and postseismic slip is not occurring at the same location. It is difficult to demonstrate rigorously that interseismic and postseismic rakes differ significantly when considered at the same location on the fault, due to the lack of spatial resolution in the interseismic model. Now, if we consider the afterslip model in which the rake is allowed to be nonuniform (Fig. 6c), it shows a rake of about $285^{\circ}$ in the area with maximum afterslip (area $A$ in Fig. 6b). It is meaningful to compare the interseismic and postseismic rake there because this area beneath the Central Range is with significant slip in the interseismic period as well as in the postseismic period. We therefore conclude that in area $A$ the coseismic 
Table 2

The stress tensors obtained in area $A$ and area B (Fig. 9) are characterized by strikes and plunges of the three principal stress axes, $\sigma_{1}, \sigma_{2}$ and $\sigma_{3}$, in degrees

\begin{tabular}{|c|c|c|c|c|c|c|c|c|c|c|}
\hline & \multirow{2}{*}{$\begin{array}{l}\text { Number } \\
\text { of events }\end{array}$} & \multicolumn{2}{|c|}{$\sigma_{1}$} & \multicolumn{2}{|c|}{$\sigma_{2}$} & \multicolumn{2}{|c|}{$\sigma_{3}$} & \multirow{2}{*}{$\begin{array}{c}\varphi^{a} \\
\frac{\sigma_{2}-\sigma_{3}}{\sigma_{1}-\sigma_{3}}\end{array}$} & \multirow[t]{2}{*}{$A z i_{\text {stress }}^{b}$} & \multirow[t]{2}{*}{$A z i_{\text {slip }}^{c}$} \\
\hline & & strike & plunge & strike & plunge & strike & plunge & & & \\
\hline South $^{1}(A)$ & 59 & $287^{\circ}$ & $19^{\circ}$ & $196^{\circ}$ & $2^{\circ}$ & $100^{\circ}$ & $71^{\circ}$ & 0.48 & $286^{\circ} \pm 6^{\circ}$ & $285^{\circ}$ \\
\hline $\operatorname{North}^{1}(B)$ & 33 & $134^{\circ}$ & $3^{\circ}$ & $296^{\circ}$ & $87^{\circ}$ & $44^{\circ}$ & $1^{\circ}$ & 0.56 & $206^{\circ} \pm 61^{\circ}$ & $300^{\circ}$ \\
\hline $\operatorname{South}^{2}(A)$ & 40 & $288^{\circ}$ & $24^{\circ}$ & $28^{\circ}$ & $22^{\circ}$ & $155^{\circ}$ & $57^{\circ}$ & 0.66 & $298^{\circ} \pm 10^{\circ}$ & $285^{\circ}$ \\
\hline $\operatorname{North}^{2}(B)$ & 41 & $129^{\circ}$ & $4^{\circ}$ & $5^{\circ}$ & $82^{\circ}$ & $219^{\circ}$ & $7^{\circ}$ & 0.27 & $275^{\circ} \pm 66^{\circ}$ & $300^{\circ}$ \\
\hline South $^{3}(A)$ & 42 & $287^{\circ}$ & $27^{\circ}$ & $21^{\circ}$ & $10^{\circ}$ & $129^{\circ}$ & $61^{\circ}$ & 0.68 & $291^{\circ} \pm 4^{\circ}$ & $285^{\circ}$ \\
\hline $\operatorname{North}^{3}(B)$ & 70 & $129^{\circ}$ & $6^{\circ}$ & $343^{\circ}$ & $83^{\circ}$ & $220^{\circ}$ & $4^{\circ}$ & 0.40 & $252^{\circ} \pm 38^{\circ}$ & $300^{\circ}$ \\
\hline
\end{tabular}

a The parameter, $\varphi$, is the ratio of the principal stress difference.

b The azimuth of the shear stress computed on a horizontal décollement with $95 \%$ confidence interval based on the bootstrap result of 1000 resampling focal mechanism data sets.

c The azimuth of postseismic slip on a horizontal décollement.

1 Data from CWB and BATS with magnitude larger than 4 and focal depth less than $35 \mathrm{~km}$.

2 Data from Wu et al. (2008) with magnitude larger than 4 and focal depth less than $20 \mathrm{~km}$.

3 Data from Wu et al. (2008) with magnitude larger than 4 and focal depth less than $35 \mathrm{~km}$.

stress change seems to have induced a notable change of slip azimuth. By contrast, Figure 6c shows no significant difference of slip azimuth in area $B$ (as defined in Fig. 6b); while this is the area where the difference between interseismic and postseismic azimuths of displacements at the GPS sites is most significant. One reason might be that the assumption of a uniform slip azimuth does not allow to fit favourable of the observed azimuths of interseismic displacements in area $B$ as seen in Figure 7. It suggests that the interseismic fault slip azimuth might trend more northerly in this area than predicted by the uniform rake model. If so, the azimuth of slip on the décollement would also have rotated counterclockwise in area $B$ due to the Chi-Chi earthquake. However, we are unable to estimate well that rotation based on the modeling presented here.

\subsection{Comparison of Fault-Slip and Shear Stress Azimuths}

We now test the hypothesis that slip on the décollement is parallel to the shear stress acting on it. To do so, we have analyzed earthquake focal mechanisms determined from first motion data by the Central Weather Bureau (CWB) (http://www.cwb.gov.tw/) and from the modeling of broadband waveforms recorded by the Broadband Array in Taiwan for Seismology (BATS, http://www.earth.sinica.edu.tw/). Because of the scarcity of earthquakes in the Chi-Chi rupture area prior to 1999, we could only carry this analysis for the postseismic period. We used the algorithm based on minimizing the misfit of the rake angle between the assumed and inverted stress tensors for both fault plane solutions to determine the orientation of the principal stress (Michael, 1984; 1987). The result of the stress inversion is given in Table 2. We consider two areas (labels $A$ and $B$ in Fig. 9). The focal mechanisms within area $A$ are consistent with a relatively homogeneous stress 


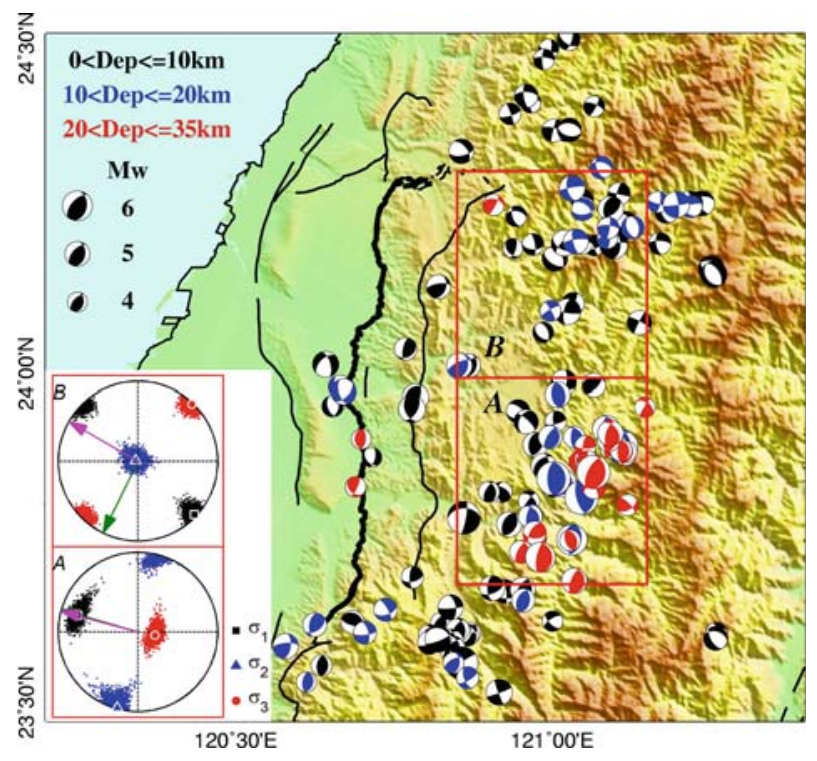

Figure 9

Focal mechanisms of aftershocks with $\mathrm{M}_{\mathrm{w}}>4$, over the first 15 months following the Chi-Chi main shock. The color code indicates focal depths. Major faults are shown in black and the 1999 Chi-Chi rupture is shown in a thicker black line. Red boxes indicate the two regions ( $A$ : south, $B$ : north) within which the stress tensors are determined from earthquake focal mechanisms. The resulting stress tensors are shown in the bottom left inset. Different symbols representing three principal axes plotted in equal-area projection of the lower hemisphere. The dots show the distributions of stress axes within $95 \%$ confidence region. Magenta and green vectors are azimuths of postseismic slip and of the shear stress computed on the flat décollement at a depth of about $12 \mathrm{~km}$.

field. To test the sensibility of the result to the assumed depth range and to the focal mechanism data sets, we have varied the depth range and considered another data set obtained from first motions analysis determined from seismic and accelerometric records (Wu et al., 2008). The stress tensor in area $A$ only varies slightly (Table 2), with the azimuth of shear stress on the décollement always close to $\mathrm{N} 285^{\circ}$. The focal mechanisms within area $B$ are more diverse and the results are more sensitive to the data set used in the inversion. It could result from a depth variation or a stronger heterogeneity of the stress tensor in area $B$ than in area $A$. In any case, the focal mechanisms are generally consistent with the vertical axis being close to a principal stress direction.

Next, we compare the azimuth of the shear stress computed from the stress tensors with the azimuth of slip on the décollement (Table 2). Our analysis demonstrates that the shear stress and shear strain azimuths on the décollement are coherent. For area $A$, the result indicates that the azimuth of slip on the décollement inferred from the geodetic data is reasonably consistent with the stress tensor obtained from earthquakes with focal depths less than $35 \mathrm{~km}$, which occurred within 15 months after the Chi-Chi earthquake (the same period as the time span covered by the postseismic GPS displacements analyzed here). In addition, if we constrain the postseismic slip azimuth on the 
décollement to be equal to the azimuth of shear stress, it yields a value of $\chi_{r}^{2}$ about 8.7 , which approaches the value of 8.5 obtained for the best-fitting slip azimuth. For area $B$, the hypothesis is contradicted. One possible explanation would be that the stress field, as revealed by the focal mechanisms, is quite heterogeneous and not representative of the shear stress on the décollement. In addition, because the intermediate principal stress component is nearly vertical, the azimuth of the shear stress on the décollement is very sensitive to the assumed attitude of the décollement (taken horizontal here). Alternatively, our estimate of the azimuth of postseismic slip on the décollement might be erroneous due to the scarcity of pre-Chi-Chi GPS data in this area. Therefore, we only focus on area $A$ in the following section.

\subsection{Implications for Shear Stress Level}

Here, we assume that the difference between interseismic and postseismic rakes reflects a change of the stress acting on the décollement, due to the fact that the postseismic stress, $\underline{\underline{\sigma}}^{\text {post }}$, is the sum of the preseismic stress, $\underline{\underline{\sigma}}^{\text {pre }}$, and the coseismic stress change, $\underline{\underline{\Delta \sigma}}$. In theory, if $\underline{\underline{\Delta \sigma}}$ is known, it is then possible to place constraints on the preand postseismic stress acting on the décollement, based on the assumption that the rotation of the shear stress is equal to the rotation of the slip azimuth. It might be assumed that the normal stress, i.e. the vertical stress, is only slightly affected by the coseismic stress change. In that case, a simple vector diagram can be constructed to estimate the magnitude of the pre- and postseismic shear stresses on the décollement. We estimate the coseismic stress change beneath the Central Range using the coseismic slip model (Fig. 4). The coseismic stress change in the box $A$ (Fig. 9) is estimated by taking the average stress change of 1000 points within a $1000 \mathrm{~km}^{3}$ cube centered at the grid point to avoid biased results from short-wavelength variations of the stress field. The averaged coseismic shear stress at $12 \mathrm{~km}$ depth on the décollement is of the order of $1 \mathrm{MPa}$ in the direction of $330^{\circ}$ within area $A$. The azimuths of preseismic and postseismic shear stress are $304^{\circ}$ and $285^{\circ}$, respectively. Based on the vector diagram, we estimate that the preseismic and postseismic shear stress in area $A$ are $2.2 \pm 2.2 \mathrm{MPa}$ and $1.3 \pm 1.4 \mathrm{MPa}$, respectively. The uncertainties given here were estimated assuming that the uncertainties on the azimuths of preseismic, coseismic, and postseismic shear stresses are $5^{\circ}, 5^{\circ}$, and $10^{\circ}$, respectively, and that the uncertainty on the amplitude of coseismic stress is $1 \mathrm{MPa}$.

Another approach consists in considering that the postseismic stress tensor acting on the décollement is correctly represented by the stress tensor determined from focal mechanisms. In that case, the normal stress change is also taken into account in the computation. If $\underline{\underline{\Delta \sigma}}$ is known and if the orientation of the principal postseismic stress and the stress ratio $\left.\overline{\overline{\phi(}}=\sigma_{2}-\sigma_{3} / \sigma_{1}-\sigma_{3}\right)$ are constrained from the focal mechanisms of the aftershocks, the postseismic differential stress, $\sigma_{1}-\sigma_{3}$, can then be determined from the condition that preseismic shear stress be colinear with the preseismic slip on the décollement. We assume a postseismic stress tensor with principal stress orientations and ratio $\phi$ constrained from the Chi-Chi aftershocks (bold text in Table 2) and a differential 


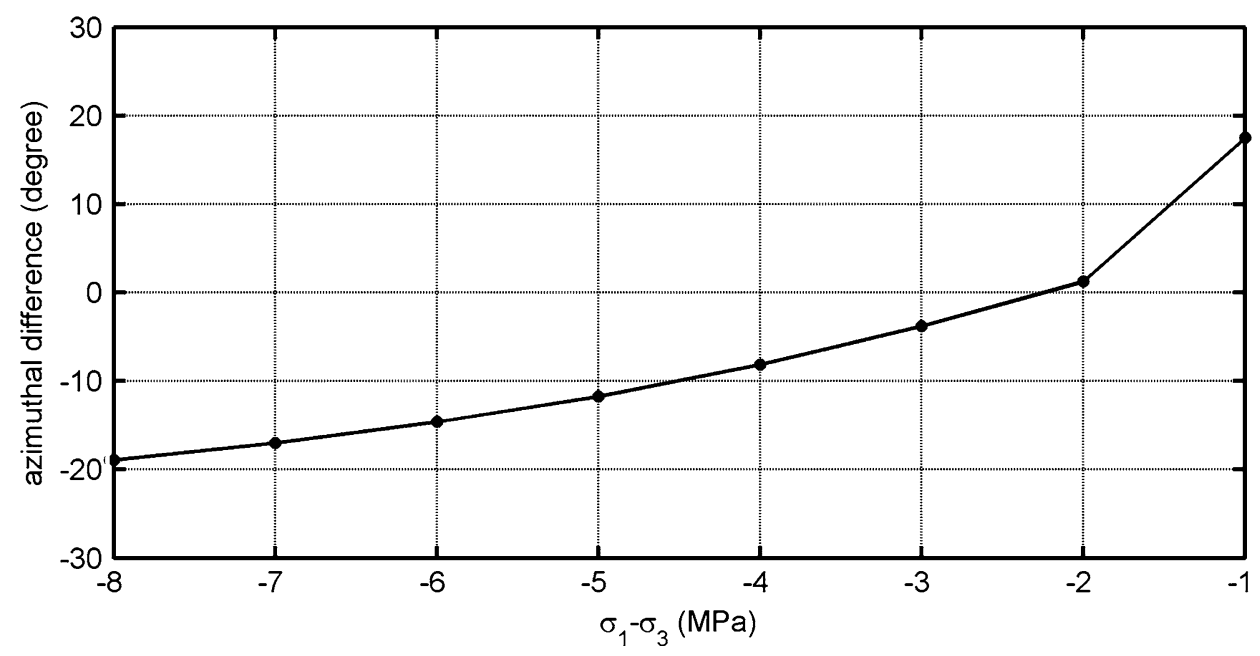

Figure 10

Difference between the azimuths of preseismic shear stress and interseismic slip as a function of differential postseismic stress for area $A$.

stress between 1 and $8 \mathrm{MPa}$. We then solve for the value of the postseismic differential stress that yields the smallest magnitude azimuthal difference between the preseismic shear stress and the preseismic slip on the décollement. Note that the colinearity is not guaranteed. The result shows that the azimuthal difference between the preseismic shear stress and the preseismic slip on the décollement is the minimum for the postseismic differential stress of $2 \mathrm{MPa}$ in area $A$ (Fig. 10). According to this reasoning, the low shear stress acting on the décollement would result from both a geometric effect, one principal stress component being near vertical, and from a low deviatoric stress within the wedge.

\section{Discussion}

\subsection{Comparison of Interseismic, Coseismic and Postseismic Slip Models}

Figures 4, 6, and 7d allow comparison of the distributions of coseismic slip, afterslip and interseismic slip rates. The three distributions complement each other and the following points can be made:

1. The area that ruptured in 1999 was strongly locked before the main shock. There is no evidence that the rupture propagated into the area that was creeping before the earthquake.

2. Not all of the area that was strongly locked before 1999 ruptured during the Chi-Chi earthquake. The interseismic model shows strong locking at shallow depths on the 


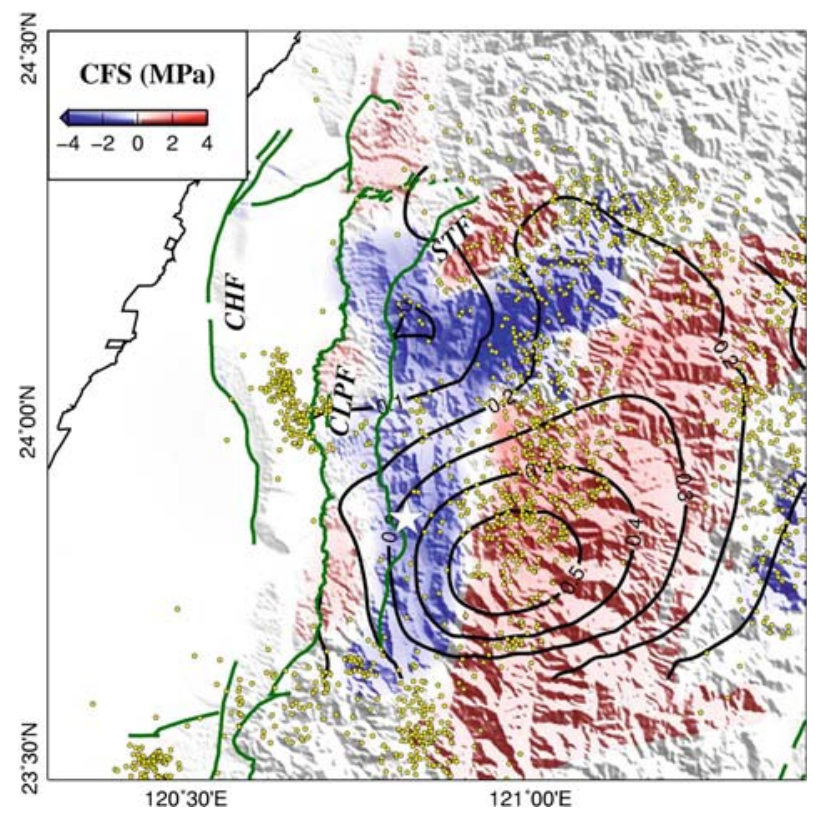

Figure 11

Comparison of afterslip distribution and coseismic Coulomb stress change on the décollement. The Coulomb stress changes (color) were computed assuming an average fault strike of $0^{\circ}$, dip angle of $10^{\circ}$, and a rake of $90^{\circ}$ at $15 \mathrm{~km}$ depth. Black contours with interval of $0.1 \mathrm{~m}$ indicate postseismic slip. White star denotes the epicenter. Yellow dots indicate aftershocks occur at depths ranging from 10 and $20 \mathrm{~km}$ over a 15 -month period after the main shock.

southern segment of the Chelungpu fault where the earthquake did not produce much slip in 1999, was not creeping before 1999, and did not experience much afterslip.

3. Afterslip occurred dominantly downdip from the rupture area of the Chi-Chi earthquake in a transition zone that was creeping before 1999, so it was probably characterized by a rate-strengthening friction. On this creeping zone, the coseismic deformation has induced a significant increase of Coulomb stress of about $1 \mathrm{MPa}$ at $15 \mathrm{~km}$ depth based on a fault geometry with $\mathrm{N}-\mathrm{S}$ trending, $10^{\circ}$ east dipping as illustrated in Figure 11. The area with the increase of Coulomb stress is consistent with the aftershock distribution at 10-20 km depth.

To first-order, this simple picture compares well to theoretical models of the seismic cycle based on the depth variation of frictional properties of faults (LAPUSTA et al., 2000; Scholz, 1998; Tse and Rice, 1986) (Fig. 12). Steady aseismic slip occurs at deep depths in the interseismic period until the instability results in a coseismic rupture at shallow depths. The relaxation of the coseismic stress causes afterslip downdip from the coseismic rupture in the postseismic period. However, afterslip does not completely fill the gap between coseismic and interseismic slip distributions. Given the relatively rapid decay of afterslip rate, the misfit is not due to the short period of afterslip considered here. 


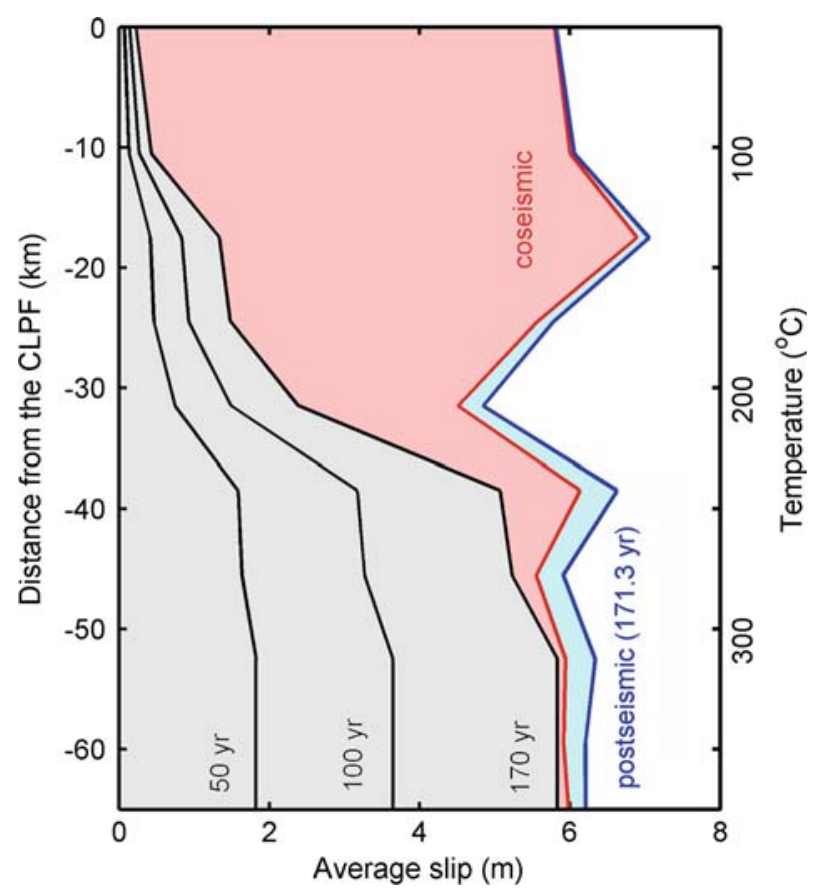

Figure 12

Average slip as a function of distance and temperature over the seismic cycle of the Chelungpu fault. The plot was obtained from determining the average coseismic slip, afterslip and interseismic slip within a 5-km wide swath along a profile parallel to $340^{\circ}$ (close to AA' in Fig. 3). Interseismic slip is from Model 3 in Figure $7 \mathrm{~d}$.

The Chi-Chi earthquake has the unusual property of having released most of its moment at relatively shallow depths. Indeed, in examples where coseismic slip could be constrained from geodetic and remote-sensing data, the maximum slip is generally found at a depth of about 5-10 km. (e.g., Avouac et al., 2006; FialKo et al., 2005; KonCa et al., 2007; Simons et al., 2002). In addition, the Chi-Chi earthquake only released slight moment on the southern segment. Other earthquakes rupturing the western foothills might release a larger proportion of moment at depths or on the southern segment. Consequently it is possible that the area of the Chelungpu fault that remains locked in the interseismic period produces a variety of coseismic ruptures. Each earthquake would have a different coseismic slip distribution however the various types of earthquakes would collectively add to aseismic slip (interseismic or postseismic) and even out the cumulative slip distribution. Another possibility is that aseismic transients, not observed during the period covered by our geodetic data, might occur in the transition zone. In any case, the Chelungpu fault must produce earthquakes with different slip distributions than the Chi-Chi event since there is no indication that the slip rate on the fault decreases southwards as does the coseismic slip. 
Figure $3 b$ shows that many aftershocks occurred at depth deeper than the brittle-ductile transition inferred from the geodetic data. These deep aftershocks may reflect heterogeneities of crustal rheology or a transient deepening of the brittle-ductile transition depth due to the large strain rates generated by the main shock rupture below the décollement. Transient deepening of the brittle-ductile transition has been simulated in numerical experiment (Ben-Zion and LyakHOvsky, 2006), and advocated for in some observational studies (RolANDONE et al., 2004; SchAFF et al., 2002).

Interestingly, the Chi-Chi earthquake nucleated near the downdip edge of the locked fault zone (see epicenter location in Fig. 7d), as is also observed in numerical experiments (LAPUSTA et al., 2000). It should be noticed that, in these models, temperature is thought to be the key parameter controlling the transition from rate-weakening at shallow depths to rate-strengthening at greater depths. We assess this possibility in the following section.

\subsection{Effect of Temperature on Fault Friction}

Temperature is thought to be a controlling parameter determining the mode of slip on subduction megathrust (Hyndman et al., 1997; Oleskevich et al., 1999; Peacock and Hyndman, 1999) as well as on intracontinental faults (BLANPIED et al., 1995). To assess the temperature on the Chelungpu fault and its downdip continuation as a décollement, we use the thermal model (SimOes et al., 2007a) that has been derived from the modeling of thermochronological and thermometric data along three sections across Taiwan. We find that aseismic slip in the interseismic and postseismic periods is dominant where temperature exceeds approximately $200^{\circ} \mathrm{C}$ (Figs. 7 and 12), a similar feature as also reported in the Nepal Himalaya based on the same approach (AvouAc, 2003). This temperature is consistent with laboratory experiments on granite at hydrothermal conditions indicating the transition from velocity-weakening friction to velocitystrengthening friction occurred around $250 \sim 350^{\circ} \mathrm{C}$, probably due to the onset of crystal plasticity of quartz (BlanPIED et al., 1995; Scholz, 1998). Temperature is thus likely a controlling parameter of downdip variations of frictional properties along the Chelungpu fault. Other parameters such as the lithology or fluid must also play a role, in particular to explain lateral variations, or shallow creep, but they are not quantified here.

\subsection{No Evidence for Shallow Creep}

At shallow depths, continental faults can sometimes exhibit a rate-strengthening frictional behavior as suggested from experimental results and the observation of shallow aseismic slip in some cases (MARONE et al., 1990; MARONE, 1998). It is then possible that fault patches with rate-strengthening friction might not creep in the interseismic period if they lie in the stress shadow of deeper locked asperities (BURGMANn et al., 2005). In that case, they would be expected to slip aseismically as a result of afterslip following the rupture of the shadowing asperities, or to eventually produce spontaneous aseismic transients (Perfettini and Ampuero, 2008). The observation of a few centimeters of 
aseismic slip on Changhua fault triggered by the Chi-Chi earthquake (PATHIER et al., 2003) suggest that this is a plausible mechanism in the context of the western foothills of Taiwan. However, in the case of the Chi-Chi earthquake, there is no shallow deficit of slip that may diagnostic a shallow rate-strengthening zone (FIALKo et al., 2005). We observe no shallow afterslip following the main shock. Therefore we exclude that there would be a significant proportion of the shallow Chelungpu fault that would be rate-strengthening but would appear locked in the interseismic period. On the other hand, some afterslip seems to overlap with the area that is locked in the interseismic period (Fig. 7c). Coseismic slip and afterslip near the hypocentral region in the southern CLPF may be an indication of a mosaic of fault patches with rate-weakening and rate-strengthening friction.

\subsection{Implications for Fault Rheology}

Our analysis reveals that the coseismic stress change related to the Chi-Chi earthquake has induced a difference in azimuth of geodetic displacements within the Central Range measured before and after the Chi-Chi earthquake. We infer that the shear-stress acting on the décollement is of the same order of magnitude as the coseismic stress change beneath the Central Range, estimated to about $1 \mathrm{MPa}$ (Fig. 11). The modeling of that effect, assuming that deformation across the Central Range is governed by aseismic creep along a horizontal décollement, requires a very low shear stress on the décollement, of the order of only $2 \mathrm{MPa}$. The low shear stress is consistent with the fact that the focal mechanisms require one principal stress component to be near vertical. Given the $\sim 10 \mathrm{~km} \mathrm{depth}$ of that décollement and assuming a crustal density of $\sim 2.9$, this low shear stress implies a very low effective friction of $\sim 0.01$. This estimate is consistent with the inference of the low taper angle between the topographic slope and the décollement, which constitutes about $8^{\circ}$, requiring an effective basal friction lower than 0.08 (CARENA et al., 2002; SuPPE, 2007).

Deformation at 10-20 km depth beneath the Central Range, where temperature is estimated to be between 200 and $300^{\circ} \mathrm{C}$ (SimOes et al., 2007a), might occur either in the brittle or ductile regime. In any case, the exceptionally low shear stress suggests that fluid is probably playing a key role. The presence of fluids is suggested by the high conductivity measured from magnetotelluric sounding (CHEN and CHEN, 2002) and a localized zone with high $\mathrm{V}_{\mathrm{p}} / \mathrm{V}_{\mathrm{s}}$ ratio at $\sim 10 \mathrm{~km}$ depth beneath the Central Range $(\mathrm{Wu}$ et al., 2007). In addition, microstructures and abundant quartz veins within the Central Range slates are evidence of fluid-assisted deformation (CHAN et al., 2005). Finally, fluids must be released as the Chinese continental margin underthrusts the western foothills and experiences dehydration and metamorphism. In the brittle regime, fluids can contribute to a low effective friction if the pore pressure is high and enhances stable frictional sliding. Through chemical effects, fluids would also enhance pressure solution deformation (CHESTER, 1995), as well as diffusion and dislocation creep (KoHLSTEDT, 1995)

As reported, frictional afterslip can explain the temporal evolution of geodetic deformation following the Chi-Chi earthquake (Hsu et al., 2007; Perfettini and Avouac, 2004) and we shall therefore start by considering this mechanism. Rock friction 
experiments have shown that that the relationship between stress and sliding velocity during rate-strengthening friction can generally be written

$$
\tau_{s s}=\sigma_{n} \mu^{*}+(a-b) \sigma_{n} \ln \left(V / V^{*}\right),
$$

where $\tau_{s s}$ is the driving shear stress, $\sigma_{n}$ is the normal stress, $(a-b)>0$ is a rheological parameter, $V$ is the sliding velocity, and $\mu^{*}$ and $V^{*}$ are the reference values. This phenomenological law seems to hold for temperatures reaching about $300^{\circ} \mathrm{C}$ for quartzofeldspathic rocks, even when deformation is assisted by fluid or distributed within some gouge zone with finite thickness (BlanPied et al., 1995; Chester, 1995; Marone, 1998).

In the steady-state approximation and assuming that the creeping velocity just before the coseismic stress change applied is equal to the asymptotic creeping velocity, $V_{o}$, afterslip rate should decay according to Perfettini and Avouac (2004)

$$
V(t)=V_{0} \frac{d \exp \left(t / t_{r}\right)}{1+d\left(\exp \left(t / t_{r}\right)-1\right)},
$$

where $d$ is the velocity jump due to coseismic stress change; $t_{r}$ is the relaxation time associated with frictional afterslip and $t$ is time after the main shock.

We have extracted the slip history (Hsu et al., 2007) in two areas ( $A$ and $B$ in Fig. 9) to test the model predictions. In both cases, the temporal decay (Fig. 13) is consistent

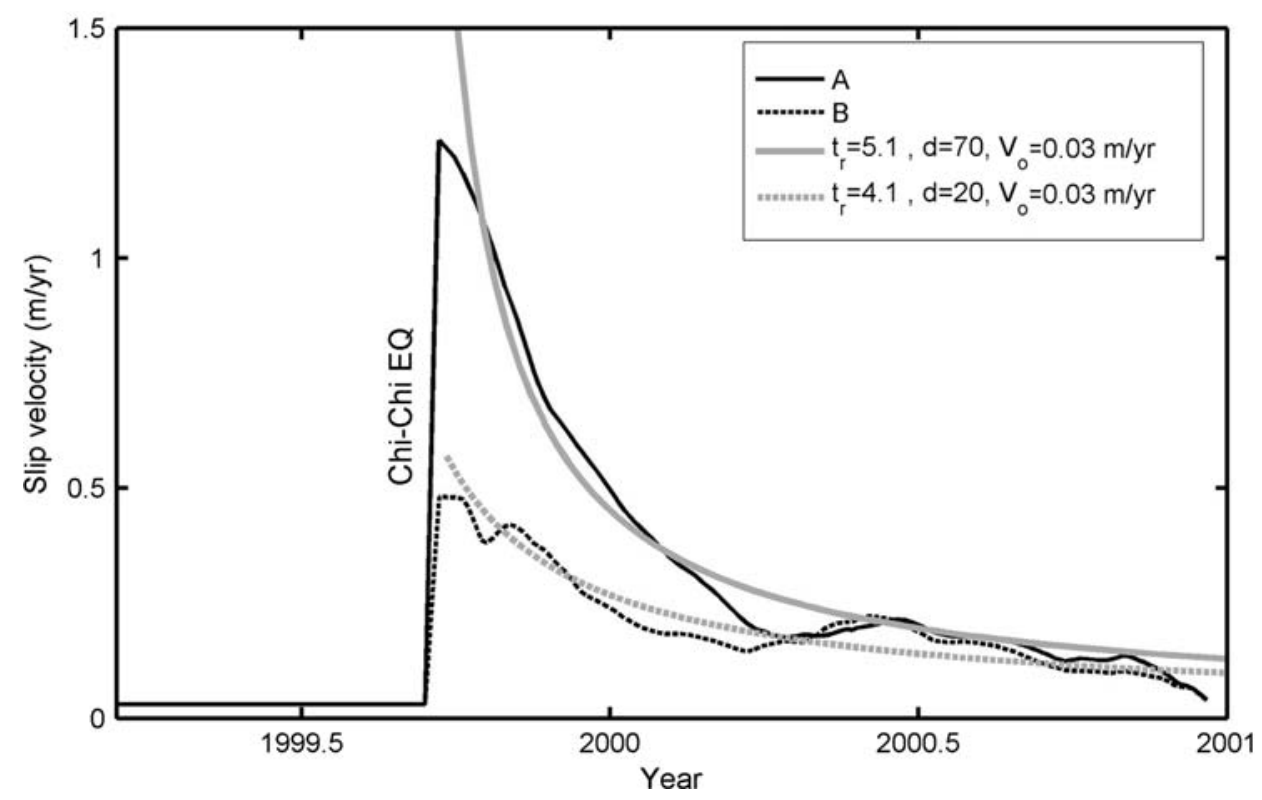

Figure 13

Temporal evolution of slip (black curves) due to afterslip computed at two locations $A$ and $B$ as indicated in Figure 6b, based on the afterslip model of Hsu et al., 2007. They are compared to the predictions of afterslip (grey curves) from a 1-D rate-strengthening frictional model (Perfettini and Avouac, 2004) (equation (4)). 
with that predicted from equation (4). The two parameters, the relaxation time $\left(t_{r}\right)$ and the velocity jump $(d)$, are solved by grid search. The value of $(a-b) \cdot \sigma_{n}$ can then be estimated from $(a-b) \cdot \sigma_{n}=\Delta C F S / \log (d)=t_{r} / T_{\text {inter }} \Delta C F S$ (Perfettini and Avouac, 2004). The coseismic Coulomb stress change $(\triangle C F S)$ is estimated to $\sim 10 \mathrm{MPa}$, and the average time interval between two earthquakes $\left(T_{\text {inter }}\right)$ similar to the Chi-Chi event is estimated to $\sim 200$ years. We infer $(a-b) \cdot \sigma_{n}$ to $0.3-2.4 \mathrm{MPa}$ and 0.2-3.3 MPa in area $A$ and $B$, respectively. Altogether, we estimate $(a-b) \cdot \sigma_{n}$ to about $0.2-3.3 \mathrm{MPa}$. Assuming a hydrostatic pore pressure, a crustal density of 2.9, and a décollement depth of $10 \mathrm{~km}$, it would imply a value of $(a-b)$ of about $8 \times 10^{-3}$. This value is in agreement with estimates derived from laboratory experiments which range from $5 \times 10^{-3}$ to $3.0 \times 10^{-2}$ (MARONE, 1998), or from postseismic observations, which fall in the range $10^{-2}-10^{-4}$ (HeARn et al., 2002; Hsu et al., 2006; Johnson et al., 2006; MiYAZAKi et al., 2004; Perfettini and Avouac, 2004; Perfettini et al., 2005)

\subsection{Return Period of Seismic Ruptures across the Western Foothills of Central Taiwan}

Interseismic strain implies a rate of accumulation of moment deficit which can be computed from integrating the slip-rate deficit over the locked fault zones. This rate is estimated to between $1.2 \times 10^{18}$ and $3.7 \times 10^{18} \mathrm{~N}$-m/yr (Table 1). If a large earthquake like the Chi-Chi earthquake were the only type of event releasing the slip deficit on the fault portion that is locked in the interseismic period, it would take about $100 \sim 300$ years to accumulate enough deficit to produce an earthquake as large as the Chi-Chi earthquake. A similar estimate, although less well-constrained by the geodetic data, was obtained by Simoes et al. (2007b). However, as mentioned above, it is clear that the real behavior is not the simple regular repetition of the Chi-Chi type earthquakes. First, the slip distributions during successive ruptures of the Chelungpu fault cannot be similar to that observed in 1999 since they must add to an approximately uniform cumulative slip distribution. If coseismic slip at one point on the fault is relatively constant from one event to another as is often observed (SIEH, 2000), seismic ruptures should be more frequent on the southern segment than on the northern segment of the Chelungpu fault. Second, the earthquakes should be about equally distributed on the Chelungpu and Changhua faults given their similar long-term slip rates.

No earthquake as large as the Chi-Chi earthquake is known to have occurred in the area over the last few centuries. Paleoseismic investigations have revealed prehistorical ruptures with slip similar to those observed in 1999 at a few sites, however, it seems clear that these paleoseismic events occurred at different times and at different places (CHEN et al., 2004, 2007a; LeE et al., 2001a; STREIG et al., 2007). Clearly, the Chelungpu fault does not act with the repetition of a characteristic earthquake similar to the Chi-Chi event. The longest record of paleoseismic investigations, which was carried at Chushan on the southern segment of the Chelungpu fault, has revealed five different events with slip similar to that observed in 1999 over the last 2000 years. Similarly, at Shi-Jia site, three events occurred over the last 
1200 years (Streig et al., 2007). Thus the return period of large events on the Chelungpu fault seems to conflict with estimates derived from the long term slip rate and the pattern of interseismic locking. There is possibility that the paleoseismic data do not cover a long enough period to be representative of the long-term behavior of the Chelungpu fault. Another possibility is that we would underestimate grossly the fraction of aseismic slip taken up by transient aseismic slip events, and that no such aseismic transients have occurred during the period covered by the geodetic data prior to the Chi-Chi earthquake.

\section{Conclusion}

The study of coseismic, postseismic and interseismic slip distributions and the comparison with the thermal structure across the western foothills of Taiwan shed light on the parameters determining the mode of slip on crustal faults and fault rheology. We find that slip on the Chelungpu fault is dominantly aseismic at depths exceeding about $10 \mathrm{~km}$, where the temperature increases beyond about $200^{\circ} \mathrm{C}$, and is dominantly seismic at shallower depths. The downdip transition from rate-strengthening to rate-weakening friction is likely governed by temperature as it corresponds to the same range of temperature as that observed in laboratory experiments on quartzo-feldspathic rocks. Afterslip following the Chi-Chi earthquake occurred along the edge of the zone that is creeping in the interseismic period and evolved as predicted from rate-strengthening friction with the frictional parameter $\mathrm{d} \tau_{\mathrm{ss}} / \mathrm{d} \ln V$ estimated to be about $1.5 \mathrm{MPa}$. Furthermore, the absence of any significant shallow afterslip on the Chelungpu fault indicates that the shallow portion of the fault, which was locked before the Chi-Chi earthquakes, primarily obeys a rate-weakening friction law.

We explore the possibility of assessing fault-stress level by comparing fault-slip rakes in the pre- and postseismic period. Indeed, the azimuth of frictional sliding in the creeping area downdip of the seismogenic zone seems to have changed due to the coseismic stress change induced by the Chi-Chi earthquake. It is difficult to demonstrate that the data really require a significant change of fault-slip rake, however, if accepted, the observation would suggest an extremely low shear stress level on this creeping basal décollement of the order of $2 \mathrm{MPa}$. This low shear stress level is consistent with the low taper angle of the orogenic wedge and the inference that the orogenic wedge does not seem to suffer significant internal deformation as it is thrust up the basal décollement. It implies that the wedge would be overcritical, the topographic slope being steeper than that which is required for the wedge to be at the verge of brittle 'passive' failure, i.e. by thrust faulting (DAHLEN, 1990). The low basal shear stress might reflect a high pore pressure and/or a shear zone deforming by pressure-solution creep.

The rupture area of the Chi-Chi earthquake lies mainly within the area of the Chelungpu fault that was locked in the interseismic period but coseismic, interseismic and postseismic slip do not add to a uniform fault slip, if only the Chi-Chi-like rupture is assumed. The pattern of locking is probably relatively stationary, as would be expected if 
it were to relate primarily to temperature or lithology along the fault. By contrast, the seismic release process is probably quite variable with the irregular occurrences of seismic ruptures with different slip distributions. This is not unexpected, given that such a complexity can arise even on a simple fault system with geometric fault irregularities or strength heterogeneities (BEN-ZION, 2001).

\section{Acknowledgments}

We thank the editor, Dr. Y. Ben-Zion, Dr. J. C. Savage, and an anonymous reviewer for their constructive comments. We are grateful to many colleagues at the Institute of Earth Sciences, Academia Sinica, as well as the Central Weather Bureau for kindly provide geodetic and earthquake focal mechanism data. We have benefited from stimulating discussions with Mark Simons. This work was supported by the National Science Foundation grant EAR-0537625 to Caltech, the Gordon and Betty Moore Foundation, and the National Science Council of the Republic of China grant NSC 95-2119-M-001-064 -MY3. This is a contribution of Caltech Tectonics Observatory number 113 and the Institute of Earth Sciences, Academia Sinica, IESAS1335.

\section{REFERENCES}

Angelier, J., Chu, H. T., and Lee, J. C. (1997), Shear concentration in a collision zone: Kinematics of the Chihshang Fault as revealed by outcrop-scale quantification of active faulting, Longitudinal Valley, eastern Taiwan, Tectonophysics 274, 117-143.

Avouac, J. P. (2003) Mountain building, erosion and the seismic cycle in the Nepal Himalaya. In Adv. Geophys. (ed. R. Dmowska, pp. 1-79 Elsevier, Amsterdam, 2003).

Avouac, J. P., Ayoub, F., Leprince, S., Konca, O. and Helmberger, D. V. (2006), The 2005, M 7.6 Kashmir earthquake: Sub-pixel correlation of ASTER images and seismic waveforms analysis, Earth Planet. Sci. Lett. 249, 514-528.

Ben-Zion, Y. (2001), Dynamic ruptures in recent models of earthquake faults, J. Mech. Phys. Solids 49, 22092244.

Ben-Zion, Y. and Lyakhovsky, V. (2006), Analysis of aftershocks in a lithospheric model with seismogenic zone governed by damage rheology, Geophys. J. Int. 165, 197-210.

Blanpied, M. L., Lockner, D. A., and Byerlee, J. D. (1995), Frictional slip of granite at hydrothermal conditions, J. Geophys. Res. 100, 13045-13064.

Bollinger, L., Avouac, J. P., Cattin, R., and Pandey, M. R. (2004), Stress buildup in the Himalaya, J. Geophys. Res. 109, doi:10.1029/2003JB002911.

Brudy, M., Zoback, M. D., Fuchs, K., Rummel, F. and Baumgartner, J. (1997), Estimation of the complete stress tensor to $8 \mathrm{~km}$ depth in the KTB scientific drill holes: Implications for crustal strength, J. Geophys. Res. 102, 18453-18475.

Burford, R. O. and Harsh, P. W. (1980), Slip on the San Andreas fault in central California from alignment array surveys, Bull. Seismol. Soc. Am. 70, 1233-1261.

Burgmann, R., Kogan, M. G., Steblov, G. M., Hilley, G., Levin, V. E., and Apel, E. (2005), Interseismic coupling and asperity distribution along the Kamchatka subduction zone, J. Geophys. Res. 110, 10.1029/ 2005JB003648.

Byerlee, J. (1978), Friction of Rocks, Pure Appl. Geophys. 116, 615-626.

Carena, S., Suppe, J. and KaO, H. (2002), Active detachment of Taiwan illuminated by small earthquakes and its control of first-order topography, Geology 30, 935-938. 
Cattin, R. and Avouac, J. P. (2000), Modeling mountain building and the seismic cycle in the Himalaya of Nepal, J. Geophys. Res. 105, 13389-13407.

Chan, Y. C., Окамото, K., Yui, T. F., Iızuka, Y., and Chu, H. T. (2005), Fossil fluid reservoir beneath a duplex fault structure within the Central Range of Taiwan: Implications for fluid leakage and lubrication during earthquake rupturing process, Terra Nova 17, 493-499.

Chang, C. H., Wu, Y. M., Zhaо, L., and Wu, F. T. (2007), Aftershocks of the 1999 Chi-Chi, Taiwan, earthquake: The first hour, Bull. Seismol. Soc. Am. 97, 1245-1258.

Chen, C. C. and Chen, C.-S. (2002), Sanyi-Puli conductivity anomaly in NW Taiwan and its implication for the tectonics of the 1999 Chi-Chi earthquake, Geophys. Res. Lett. 29, 1166.

Chen, W. S., Lee, K. J., Lee, L. S., Ponti, D. J., Prentice, C., Chen, Y. G., Chang, H. C., and Lee, Y. H. (2004), Paleoseismology of the Chelungpu Fault during the past 1900 years, Quaternary International 115, 167-176.

Chen, W. S., Yang, C. C., Yen, I. C., Lee, L. S., Lee, K. J., Yang, H. C., Chang, H. C., Ota, Y., Lin, C. W., Lin, W. H., Sнін, T. S., and Lu, S. T. (2007a), Late Holocene paleoseismicity of the southern part of the Chelungpu fault in central Taiwan: Evidence from the Chushan excavation site, Bull. Seismol. Soc. Am. 97, 1-13.

Chen, Y. G., Lai, K. Y., Lee, Y. H., Suppe, J., Chen, W. S., Lin, Y. N. N., Wang, Y., Hung, J. H., and Kuo, Y. T. (2007b), Coseismic fold scarps and their kinematic behavior in the 1999 Chi-Chi earthquake Taiwan, J. Geophys. Res. 112, doi:10.1029/2006JB004388.

Chester, F. M. (1995), A rheologic model for wet crust applied to strike-slip faults, J. Geophys. Res. 100, 13033-13044.

DAHLEN, F. A. (1990), Critical taper model of fold-and-thrust belts and accretionary wedges, Annu. Rev. Earth Planet. Sci. 18, 55-99.

Davis, D., Suppe, J. and Dahlen, F. A. (1983), Mechanics of fold-and-thrust belts and accretionary wedges, J. Geophys. Res. 88, 1153-1172.

Dominguez, S., Avouac, J. P., and Michel, R. (2003), Horizontal coseismic deformation of the 1999 Chi-Chi earthquake measured from SPOT satellite images: Implications for the seismic cycle along the western foothills of central Taiwan, J. Geophys. Res. 108, doi:10.1029/2001JB000951.

Fialko, Y., Sandwell, D., Simons, M., and Rosen, P. (2005), Three-dimensional deformation caused by the Bam, Iran, earthquake and the origin of shallow slip deficit, Nature, 435, 295-299.

HaRdebeck, J. L. and Hauksson, E. (2001), Crustal stress field in southern California and its implications for fault mechanics, J. Geophys. Res. 106, 21859-21882.

Hauksson, E. (1990), Earthquakes, faulting and stress in the Los Angeles Basin, J. Geophys. Res. 95, 15,365315,394 .

Hearn, E. H., Burgmann, R., and Reilinger, R. E. (2002), Dynamics of Izmit earthquake postseismic deformation and loading of the Duzce earthquake hypocenter, Bull. Seismol. Soc. Am. 92, 172-193.

Hsu, Y.-J., Simons, M., Yu, S.-B., Kuo, L.-C., and CHEN, H.-Y. (2003), A two-dimensional dislocation model for interseismic deformation of the Taiwan mountain belt., Earth Planet. Sci. Lett. 211, 287-294.

Hsu, Y. J., Bechor, N., Segall, P., Yu, S.-B., Kuo, L. C., and Ma, K. F. (2002), Rapid afterslip following the 1999 Chi-Chi, Taiwan earthquake, Geophys. Res. Lett. 29, 10.1029/2002GL014967.

Hsu, Y. J., Simons, M., Avouac, J. P., Galetzka, J., Sieh, K., Chlieh, M., Natawidjaja, D., Prawirodirdjo, L., and Воск, Y. (2006), Frictional afterslip following the 2005 Nias-Simeulue earthquake, Sumatra, Science 312, 1921-1926.

Hsu, Y. J., Segall, P., Yu, S. B., Kuo, L. C., and Williams, C. A. (2007), Temporal and spatial variations of postseismic deformation following the 1999 Chi-Chi, Taiwan earthquake, Geophys. J. Int. 169, 367-379.

Hyndman, R. D., Yamano, M., and Oleskevich, D. A. (1997), The seismogenic zone of subduction thrust faults, The Island Arc, 6, 244-260.

Ji, C., Helmberger, D. V., Song, T.-R. A., MA, K.-F., and Wald, D. J. (2001), Slip distribution and tectonic implications of the 1999 Chi-Chi, Taiwan earthquake, Geophys. Res. Lett. 28, 4379-4382.

Ji, C., Helmberger, D. V., Wald, D. J., and MA, K. F. (2003), Slip history and dynamic implications of the 1999 Chi-Chi, Taiwan, earthquake, J. Geophys. Res. 108, doi:10.1029/2002JB001764.

Johnson, K. J., Hsu, Y.-J., Segall, P., and Yu, S.-B. (2001), Fault geometry and slip distribution of the 1999 Chi-Chi, Taiwan earthquake imaged from inversion of GPS data, Geophys. Res. Lett. 28, 2285-2288.

Johnson, K. M. and Segall, P. (2004), Imaging the ramp-decollement geometry of the Chelungpu fault using coseismic GPS displacements from the 1999 Chi-Chi, Taiwan earthquake, Tectonophysics 378, 123-139. 
Johnson, K. M., Burgmann, R., and Larson, K. (2006), Frictional properties on the San Andreas fault near Parkfield, California, inferred from models of afterslip following the 2004 earthquake, Bull. Seismol. Soc. Am. 96, S321-S338.

Jones, L. M. (1988), Focal mechanisms and the state of stress on the San Andreas fault in southern California, J. Geophys. Res. 93, 8869-8891.

Kohlstedt, D. L., Evans, B., and Mackwell, S. J. (1995), Strength of the lithosphere: Constraints imposed by laboratory experiments, J. Geophys. Res. 100, 587-517,602.

Konca, A. O., Huorleifsdottir, V., Song, T. R. A., Avouac, J. P., Helmberger, D. V., Ji, C., Sieh, K., Briggs, R., and Meltzner, A. (2007), Rupture kinematics of the 2005 M-w 8.6 Nias-Simeulue earthquake from the joint inversion of seismic and geodetic data, Bull. Seismol. Soc. Am., 97, S307-S322.

Lapusta, N., Rice, J. R., Ben-Zion, Y., and Zheng, G. T. (2000), Elastodynamic analysis for slow tectonic loading with spontaneous rupture episodes on faults with rate- and state-dependent friction, J. Geophys. Res., 105, 23765-23789.

Lee, J.-C., Chen, Y.-G., Sieh, K., Mueller, K., Chen, W.-S., Chu, H.-T., Chan, Y.-C., Rubin, C., and Yeats, R. (2001a), A vertical exposure of the 1999 surface rupture of the Chelungpu fault at Wufeng, western Taiwan: Structural and paleoseismic implications for an active thrust fault, Bull. Seismol. Soc. Am. 91, 914-929.

Lee, J. C., Angelier, J., Chu, H. T., Hu, J. C., and Jeng, F. S. (2001b), Continuous monitoring of an active fault in a plate suture zone: a creepmeter study of the Chihshang Fault, eastern Taiwan, Tectonophysics 333, 219-240.

Lee, J. C., Angelier, J., Chu, H. T., Hu, J. C., Jeng, F. S., and RAu, R. J. (2003), Active fault creep variations at Chihshang, Taiwan, revealed by creep meter monitoring, 1998-2001, J. Geophys. Res. 108, doi:10.1029/ 2003JB002394.

Lisowski, M. and Prescott, W. H. (1981), Short range distance measurements along the San Andreas fault system in central California, Bull. Seismol. Soc. Am., 71, 1607-1624.

Liu, C. C. and Yu, S.-B. (1990), Vertical crustal movements in eastern Taiwan and their tectonic implications, Tectonophysics 183, 111-119.

Loevenbruck, A., Cattin, R., Le Pichon, X., Courty, M. L., and Yu, S. B. (2001), Seismic cycle in Taiwan derived from GPS measurements, Comptes Rendus De L Academie Des Sciences Serie Ii Fascicule a-Sciences De La Terre Et Des Planetes, 333, 57-64.

Loevenbruck, A., Cattin, R., Le Pichon X., Dominguez, S., and Michel, R. (2004), Coseismic slip resolution and postseismic relaxation time of the 1999 Chi-Chi, Taiwan, earthquake as constrained by geological observations, geodetic measurements and seismicity, Geophys. J. Int. 158, 310-326.

Marone, C., Raleigh, C. B., and Scholz, C. (1990), Frictional behavior and constitutive modelling of simulated fault gouge, J. Geophys. Res. 95, 7007-7025.

Marone, C. (1998), Laboratory-derived friction laws and their application to seismic faulting, Annu. Rev. Earth Planet. Sci. 26, 643-696.

Matthews, M. V. and SEgall, P. (1993), Estimation of depth-dependent fault slip from measured surface deformation with application to the 1906 San Francisco earthquake, J. Geophys. Res. 98, 12,153-112,163.

Michael, A. J. (1984), Determination of stress from slip data - faults and folds, J. Geophys. Res. 89, 1517-1526.

Michael, A. J. (1987), Use offocal mechanisms to determine Stress - A control study, J. Geophys. Res. 92, 357-368.

Miyazaki, S., Segall, P., Fukuda, J., and Kato, T. (2004), Space time distribution of afterslip following the 2003 Tokachi-oki earthquake: Implications for variations in fault zone frictional properties, Geophys. Res. Lett. 31, doi:10.1029/2003GL019410.

Mount, V. S. and SupPe, J. (1987), State of stress near the San-Andreas fault - Implications for wrench tectonics, Geology 15, 1143-1146.

Окара, Y. (1985), Surface deformation to shear and tensile faults in a half space, Bull. Seism. Soc. Am. 75, 1135-1154.

Oleskevich, D. A., Hyndman, R. D., and Wang, K. (1999), The updip and downdip limits to great subduction earthquakes: Thermal and structural models of Cascadia, south Alaska, SW Japan, and Chile, J. Geophys. Res. 104, 14965-14991.

Pathier, E., Fruneau, B., Deffontaines, B., Angelier, J., Chang, C. P., Yu, S.-B., and Lee, C.-T. (2003), Coseismic displacements of the footwall of the Chelungpu fault caused by the 1999, Taiwan, Chi-Chi earthquake from InSAR and GPS data, Earth Planet. Sci. Lett. 212, 73-88.

Peacock, S. M. and Hyndman, R. D. (1999), Hydrous minerals in the mantle wedge and the maximum depth of subduction thrust earthquakes, Geophys. Res. Lett. 26, 2517-2520. 
Perfettini, H. and Avouac, J. P. (2004), Postseismic relaxation driven by brittle creep: A possible mechanism to reconcile geodetic measurements and the decay rate of aftershocks, application to the Chi-Chi earthquake, Taiwan, J. Geophys. Res. 109, doi:10.1029/2003JB002488.

Perfettini, H., Avouac, J. P., and RuegG, J. C. (2005), Geodetic displacements and aftershocks following the $2001 \mathrm{Mw}=8.4$ Peru earthquake: Implications for the mechanics of the earthquake cycle along subduction zones, J. Geophys. Res. 110, doi:10.1029/2004JB003522.

Perfettini, H., and Ampuero, J. P. (2008), Dynamics of a velocity strengthening fault region: Implications for slow earthquakes and postseismic slip, J. Geophys. Res. 113, doi:10.1029/2007JB005398.

Rolandone, F., Burgmann, R., and Nadeau, R. M. (2004), The evolution of the seismic-aseismic transition during the earthquake cycle: Constraints from the time-dependent depth distribution of aftershocks, Geophys. Res. Lett. 31, 10.1029/2004GL021379.

SAVAGE, J. C. (1983), A dislocation model of strain accumulation and release at a subduction zone, J. Geophys. Res. 88, 4984-4996.

Schaff, D. P., Bokelmann, G. H. R., Beroza, G. C., Waldhauser, F., and Ellsworth, W. L. (2002), Highresolution image of Calaveras Fault seismicity, J. Geophys. Res. 107, 10.1029/2001JB000633.

Scholz, C. The Mechanics of Earthquakes and Faulting, 439 pp, (Cambridge University Press, New York 1990).

Scholz, C. H. (1998), Earthquakes and friction laws, Nature 391, 37-42.

Scholz, C. H. (2000), Evidence for a strong San Andreas fault, Geology, 28, 163-166.

SHAw, B. E. (1995), Frictional weakening and slip complexity in earthquake faults, J. Geophys. Res. 100, 18239-18251.

ShimaZaki, K. and NaKata, T. (1980), Time-predictable recurrence model for large earthquakes, Geophys. Res. Lett. 7, 279-282.

Shin, T. C. and Teng, T. L. (2001), An overview of the 1999 Chi-Chi, Taiwan, earthquake, Bull. Seismol. Soc. Am. 91, 895-913.

SiEH, K. (2000), The repetition of large earthquake ruptures, paper presented at Hokudan International Symp. and School on Active (Letter Press Co. Ltd., FaultingHokudan, Japan, 2000).

Simoes, M., Avouac, J. P., Beyssac, O., Goffe, B., Farley, K. A., and Chen, L. (2007a), Mountain building in Taiwan: A thermokinematic model, J. Geophys. Res. 112, doi: 10.1029/2006JB004824.

Simoes, M., Avouac, J. P., and Chen, Y. G. (2007b), Slip rates on the Chelungpu and Chushiang thrust faults inferred from a deformed strath terrace along the Dungpuna river, west central Taiwan, J. Geophys. Res. 112, doi:10.1029/2005JB004200.

Simons, M., Fialko, Y., and Rivera, L. (2002), Coseismic deformation from the 1999 M-w 7.1 Hector Mine, California, earthquake as inferred from InSAR and GPS observations, Bull. Seismol. Soc. Am. 92, 1390-1402.

Streig, A. R., Rubin, C. M., Chen, W. S., Chen, Y. G., Lee, L. S., Thompson, S. C. Madden, C., and Lu, S. T. (2007), Evidence for prehistoric coseismic folding along the Tsaotun segment of the Chelungpu fault near Nan-Tou, Taiwan, J. Geophys. Res. 112, doi:10.1029/2006JB004493.

SupPe, J. (2007), Absolute fault and crustal strength from wedge tapers, Geology 35, 1127-1130.

Titus, S. J., DeMets, C., and Tikoff, B. (2005), New Slip rate estimates for the creeping segment of the San Andreas fault, California, Geology 33, 161-240.

TsE, S. T., and RICE, J. R. (1986), Crustal earthquake instability in relation to depth variation of frictional slip properties, J. Geophys. Res. 91, 9452-9472.

Vergne, J., Cattin, R., and Avouac, J.-P. (2001), On the use of dislocations to model interseismic strain and stress build-up at intracontinental thrust faults, Geophys. J. Int. 147, 155-162.

Wesson, R. L., and Boyd, O. S. (2007), Stress before and after the 2002 Denali fault earthquake, Geophys. Res. Lett. 34, doi:10.1029/2007GL029189.

Wu, Y. M., Chang, C. H., Zhao, L., Shyu, J. B. H., Chen, Y. G., Sieh, K., and Avouac, J. P. (2007), Seismic tomography of Taiwan: Improved constraints from a dense network of strong motion stations, J. Geophys. Res. 112, doi:10.1029/2007JB004983.

Wu, Y. M., Zhao, L., Chang, C. H., and Hsu, Y. J. (2008), Focal-mechanism determination in Taiwan by genetic algorithm, Bull. Seismol. Soc. Am. 98, 651-661.

Yu, S.-B., Kuo, L.-C., Hsu, Y.-J., Su, H.-H., Liu, C. C., Hou, C.-S., Lee, J.-F., LaI, T.-C., Liu, C. C., Liu, C.-L., Tseng, T.-F., Tsai, C.-S., and Shin, T.-C. (2001), Preseismic deformation and coseismic displacements associated with the 1999 Chi-Chi, Taiwan, earthquake, Bull. Seismol. Soc. Am. 91, 995-1012. 
Yu, S.-B., Hsu, Y.-J., Kuo, L.-C., Chen, H.-Y., and Liu, C.-C. (2003), GPS measurements of postseismic deformation following the 1999 Chi-Chi earthquake, J. Geophys. Res. 108, 2520.

Yu, S. B. and Liu, C. C. (1989), Fault creep on the central segment of the Longitudinal Valley Fault, eastern Taiwan, Proc. Geol. Soc. China 32, 209-231.

Yu, S. B., and Kuo, L. C. (2001), Present-day crustal motion along the Longitudinal Valley Fault, eastern Taiwan, Tectonophysics 333, 199-217.

Yue, L. F., Suppe, J., and Hung, J. H. (2005), Structural geology of a classic thrust belt earthquake: the 1999 Chi-Chi earthquake Taiwan $(M-w=7.6)$, J. Struct. Geol. 27, 2058-2083.

Zoback, M. D., Zoback, M. L., Mount, V. S., Suppe, J., Eaton, J. P., Healy, J. H., Oppenheimer, D., Reasenberg, P., Jones, L., Raleigh, C. B., Wong, I. G., Scotti, O., and Wentworth, C. (1987), New Evidence on the state of stress of the San-Andreas fault system, Science 238, 1105-1111.

ZoBACK, M. D., and TownEND, J. (2001), Implications of hydrostatic pore pressures and high crustal strength for the deformation of intraplate lithosphere, Tectonophysics 336, 19-30.

(Received September 15, 2008, accepted March 3, 2009)

To access this journal online:

www.birkhauser.ch/pageoph 